\title{
Zwischen Surrealismus und Sozrealismus: Ambivalenzen der Avantgarde am Beispiel Elsa Triolet
}

\section{Einleitung}

Elsa Triolet sei «un écrivain peut-être à redécouvrir»: Diese Feststellung Alain Trouvés aus dem Jahr 2006 besitzt nach wie vor ihre Gültigkeit. ${ }^{1}$ Triolet ist zwar nie in Vergessenheit geraten; doch die Rezeption ihres Werkes litt unter ihrer politischen Stigmatisierung wie unter der Legendenbildung um Aragons mythische 〈Elsa», "partiellement responsable de l'effacement de la femme écrivain»: «La Muse ne saurait écrire», bringt Trouvé das Problem auf den Punkt. ${ }^{2}$ Ihr eigenes Euvre, teilweise der nicht recht ernst genommenen ১Jugendliteratur〉 oder auch 〈Frauenliteratur〉 zugeschlagen, tritt in den Hintergrund.

Warum Elsa Triolet in einem Band zum Thema Avantgarde? Der Fall Triolet konzentriert in besonderer Dichte manche Ambivalenzen der Avantgarde (bzw. «besser der Avantgarden», um mit Wolfgang Asholt und Walter Fähnders im Plural zu sprechen) ${ }^{3}$ und lädt insofern zu einigen prinzipiellen Reflexionen ein: Avantgarde und Migration; Avantgarde und Mehrsprachigkeit; Avantgarde und littérature engagée; Avantgarde und Politik, deren komplexe Relation nicht nur im Licht von Boris Groys' kontroversen Thesen ${ }^{4} \mathrm{zu}$ betrachten ist; Avantgarde und Marginalität; Avantgarde und Geschlecht, wobei die skizzierten Themenbereiche in ihrer Interaktion zu analysieren sind.

1 Alain Trouvé: La Lumière noire d'Elsa Triolet. Lyon: ENS Éditions 2006, S. 8.

2 Ebda., S. 7.

3 Wolfgang Asholt/Walter Fähnders: 〈Projekt Avantgarde〉. Vorwort. In: Dies. (Hg.): «Die ganze Welt ist eine Manifestation». Die europäische Avantgarde und ihre Manifeste. Darmstadt: Wiss. Buchgesellschaft 1997, S. 1-17, hier S. 4; «[...] there is no such thing as the avant-garde; there are only specific avant-garde movements, situated in a particular time and place», betont auch Susan Rubin Suleiman. In: Subversive Intent. Gender, Politics, and the Avant-Garde. Cambridge, Mass./ London: Harvard University Press 1990, S. 18.

4 Vgl. Boris Groys: Gesamtkunstwerk Stalin. Die gespaltene Kultur in der Sowjetunion. München: Hanser 1996 [1988]. 


\section{Avantgarde und Migration: Figurationen der Fremdheit}

Avantgarde und Migration: Migration als Trigger rückwärtsgewandter Nostalgie? Migration als Motor künstlerischer Innovation? Ist der Schriftsteller im Exil, wie Iosif Brodskij formuliert, «im Großen und Ganzen ein retrospektives und retroaktives Wesen»? ${ }^{5}$ "Writing is impossible without some kind of exile», erklärt Julia Kristeva $^{6}$ - ein privilegierter Exil-Begriff, den Edward Said problematisiert, ${ }^{7}$ während Vilém Flusser migrantischen Status als «zugleich negatives und positives Lebensvorzeichen», ${ }^{8}$ das Exil als «Brutstätte für schöpferische Taten, für das Neue» beschreibt. ${ }^{9}$ Gerade für Frauen können «displacement» und «dislocation», so Janet Wolff, sich als «quite strikingly productive» erweisen. ${ }^{10}$

Dies gilt in mancher Hinsicht auch für Triolet, die die Ambivalenzen des Fremdseins exemplarisch an einer Reihe von Figuren vorexerziert, so in $L e$ Rendez-vous des étrangers (1956), Porträt von Paris als Kreuzungspunkt verschiedener Emigrationskulturen, Hochburg der Avantgarden - und der kreativen «Légion Étrangère» von Montparnasse, für die Marginalität der Normalfall ist:

5 Joseph Brodsky: Der Zustand, den wir Exil nennen, oder Leinen los [1987]. In: Der sterbliche Dichter. Über Literatur, Liebschaften und Langeweile. Frankfurt a.M.: Fischer 2000 [On Grief and Reason, 1995], S. 31-46, hier S. 38.

6 Julia Kristeva: A New Type of Intellectual. The Dissident [1977]. In: Toril Moi (Hg.): The Kristeva Reader. Oxford: Blackwell 1986, S. 292-301, hier S. 298; zit. nach Anja Tippner: «Aller et retour, ou aller seulement, sans retour». Exil als Lebensform und Metapher bei Elsa Triolet und Viktor Šklovskij. In: Lyubov Bugaeva/Eva Hausbacher (Hg.): Ent-Grenzen. Intellektuelle Emigration in der russischen Kultur des 20. Jahrhunderts. Frankfurt a.M. u. a.: Lang 2006, S. 105-127, hier S. 108. 7 «Exile is strangely compelling to think about but terrible to experience. [...] On the twentiethcentury scale, exile is neither aesthetically nor humanistically comprehensible: at most the literature about exile objectifies an anguish and a predicament most people rarely experience first hand; but to think of the exile informing this literature as beneficially humanistic is to banalize its mutilations, the losses it inflicts on those who suffer them [...]», erklärt Edward W. Said (Reflections on Exile. In: Reflections on Exile and Other Essays. London: Granta 2012 [2000], S. 173-186, hier S. 173f.) - und hinterfragt auch den Mythos der Metropole Paris, «a capital famous for cosmopolitan exiles», aber eben auch «a city where unknown men and women have spent years of miserable loneliness» (ebda., S. 176). Vgl. dazu Anja Tippner: «Aller et retour...», S. 109.

8 Ebda.

9 Vilém Flusser: Exil und Kreativität [1984/1985]. In: Von der Freiheit des Migranten. Einsprüche gegen den Nationalismus. Hamburg: Europäische Verlagsanstalt 2007 [1994], S. 103-109, hier S. 109.

10 Janet Wolff: Resident Alien. Feminist Cultural Criticism. Cambridge: Polity 1995, S. 9; zit. nach Anja Tippner: «Aller et retour...», S. 117. 
«[...] la marge était la place normale pour chacun.» ${ }^{11}$ Dieser Metaroman, ${ }^{12}$ der als Meditation über den «mal du pays» beginnt und als «plaidoyer pour l'internationalisme prolétarien» endet, ${ }^{13}$ bietet «une analyse complète de la phénoménologie de l'étrangeté» ${ }^{14}$ samt Reflexion über die Nuancen des étranger, des exilé, des apatride, des métèque, aber auch über den Fremden, die Fremde als paradigmatisches (post-)modernes Subjekt. Von besonderem Interesse ist an diesem Text, dass er auch «gleichberechtigte weibliche Fremdheitsentwürfe» entfaltet; ${ }^{15}$ «the sense of exile» bei Triolet sei «also gendered», betont Diana Holmes. ${ }^{16}$ Und auch hier erscheint das Exil als «die literarischere Lebensform». ${ }^{17}$

Jener nostalgische «Retrospektivmechanismus» ${ }^{18}$ ist Triolet freilich nicht fremd; quer durch ihr Werk wird das Motiv des «mal du pays» ausgesponnen. Allerdings ergibt sich - im Gegensatz zum Gros der russischen Emigrationsliteratur der ersten Welle - insofern eine spezifische Konstellation, als sich ihr Blick zurück wesentlich auf die russische Avantgarde mit ihrer zukunftsorientierten Poetik richtet.

Triolet, später als «Stalinistin〉 verfemt, aber auch von den sowjetischen Autoritäten mit Misstrauen betrachtet, ${ }^{19}$ ist keine klassische Emigrantin ${ }^{20}$ - und im

11 Elsa Triolet: Le Rendez-vous des étrangers. Paris: Gallimard 1956, S. $19 f$.

12 Gleich mehrere «Migrationsromane» werden intradiegetisch in den Text verschachtelt: das (scheiternde) Projekt des Aristokraten Duvernois ebenso wie jenes des talentierten Mythomanen Sacha Rosenzweig, der mit seinem «Danger de mort» nur knapp den Goncourt verfehlt (ebda., S. 337ff.).

13 Elsa Triolet: [Postface]. In: L’Âme [L’Âge de nylon 3]. Paris: Gallimard 1973 [1963], S. 365; zit. nach Unda Hörner: Das Romanwerk Elsa Triolets. Im Spannungsfeld von Avantgarde und Sozialistischem Realismus. Essen: Die Blaue Eule 1993, S. 107.

14 Andrea Duranti: Elsa Triolet. Une vie étrangère. In: Thomas Stauder (Hg.): L'identité féminine dans l'œuvre d'Elsa Triolet. Tübingen: Narr 2010, S. 319-334, hier S. 325.

15 Anja Tippner: «Aller et retour...», S. 119.

16 Diana Holmes: French Women's Writing. 1848-1994 (4). London u. a.: Athlone 1996, S. 172; zit. nach Andrea Duranti: Elsa Triolet. Une vie étrangère, S. 321.

17 Anja Tippner: «Aller et retour...», S. 123.

18 Joseph Brodsky: Der Zustand, den wir Exil nennen, S. 40.

19 Ihre russischsprachigen Werke zeugten nicht von «d'opinions progressistes», sondern stellten «le tribut tardif aux sentiments décadents» dar, zitiert Tamara Balachova eine an das Zentralkomitee der KPdSU adressierte Geheimnotiz vom 16. Oktober 1954. Dies.: Le double destin d'Elsa Triolet en Russie (Documents des Archives moscovites). In: Marianne Gaudric-Delranc (Hg.): Elsa Triolet. Un écrivain dans le siècle. Paris: L'Harmattan 2000, S. 93-101, hier S. 99.

20 «[...] ni exilée, ni apatride, ni réfugiée politique, encore moins officielle des Soviets», umschreibt Lilly Marcou ex negativo Triolets «statut hors du commun». Dies.: Elsa Triolet. Les Yeux et la Mémoire. Paris: PLON 1994, S. 44. 
Kontext der antibolschewistischen «Russia Abroad» ${ }^{21}$ eine Außenseiterin, der auch noch nach Jahrzehnten heftige Antipathien entgegengebracht werden. ${ }^{22}$ «J'ai quitté la Russie en 1918 pour épouser un Français qui ne faisait pas de vers. [...] En partant j'étais sûre de revenir très vite, de faire juste un voyage», erinnert sich Triolet. ${ }^{23}$ Nach ihrer Hochzeit mit André Triolet verbringt sie ein Jahr auf Tahiti, 〈fluktuiert ${ }^{24}$ darauf zwischen Paris, London, Berlin - Zentrum einer heterogenen russischen Diaspora -, verwirft die Perspektive einer eventuellen Rückkehr nach Moskau, geht stattdessen nach Frankreich, ${ }^{25}$ reist in der Folge jedoch immer wieder in die Sowjetunion.

Bei all dem insistiert sie auf ihrem Status als «Fremde〉. Als sie sich nach dem Abschied von der Südsee bei der Familie ihres Mannes aufhält, befindet sie die französischen Provinzbewohner für «aussi insolites que les Nègres de Tahiti»; ${ }^{26}$ aber auch in Paris manifestiert sich dieser «sentiment d'étrangeté»: ${ }^{27}$ "Quand je suis rentrée en France, ce n'était pas chez moi que je rentrais, tout, à Paris, était aussi extraordinaire que dans l'île, comme les Nègres.»" ${ }^{28}$ Retrospektiv beschreibt Triolet sich in dieser Zeit als «[u]ne âme en peine, rongée par le mal du pays, seule à patauger dans mon abîme nostalgique». ${ }^{29}$ Noch Jahrzehnte später klagt sie gegenüber ihrer Schwester Lilja Brik: «J'ai fait de mon mieux pour m'intégrer, mais pour les Français je reste une étrangère.» ${ }^{30}$

21 Vgl. Marc Raeff: Russia Abroad. A Cultural History of the Russian Emigration. 1919-1939. New York/Oxford: Oxford University Press 1990.

22 Vgl. etwa Unda Hörners Schilderung ihrer Korrespondenz mit Nina Berberova, die noch 1990 ihre Aversion gegen Triolet, «un agent de Moscou», artikuliert (Das Romanwerk Elsa Triolets, S. 20).

23 Elsa Triolet: Ouverture. In: Euvres romanesques croisées d'Elsa Triolet et Aragon. Bd. 1: À Tahiti. Bonsoir, Thérèse. Les Manigances. Paris: Laffont 1964, S. 11-47, hier S. 14.

24 Vgl. Anja Tippner: «Aller et retour...», S. 116.

25 «De Berlin où j’ai bien passé un an, je suis retournée à Paris. Peut-être aurais-je pu, aurais-je dû alors rentrer dans mon pays, mais je ne crois pas y avoir seulement songé. Je n'étais plus de plain-pied avec les miens, famille ou pas: [...] Je n'avais plus de chez-moi à Moscou, j'y avais perdu ma place, et déjà j'avais Paris dans le sang», resümiert Triolet nachträglich ihre Stimmung in dieser frühen Pariser Zeit (Ouverture, S. 15f.). Doch in ihrem Journal 1928-1929 fragt sie sich wiederum: «Ou repartir en Russie? Quelle attraction l'Occident m'offre-t-il encore? Je serai bientôt tout à fait mûre pour retourner en Russie» (Écrits intimes. 1912-1939. Herausgegeben von MarieThérèse Eychart. Paris: Stock 1998, S. 220; zit. nach Anja Tippner: «Aller et retour...», S. 117).

26 Zit. nach Huguette Bouchardeau: Elsa Triolet. Écrivain. Paris: Flammarion 2000, S. 68.

27 Ebda., S. 70.

28 Zit. ebda.

29 Elsa Triolet: Ouverture, S. 15.

30 Lilly Marcou: Elsa Triolet, S. 322 (unter Verweis auf ein Gespräch mit Elizaveta Kuvšinova, 2. Mai 1993). 
«[L]es diverses variantes de l'errance», ${ }^{31}$ «isolation, solitude, and marginality ${ }^{32}$ bleiben die Leitthemen Triolets, auch abseits der Literatur («La solitude n'est pas le grand thème de mes livres, elle l'est de ma vie» ${ }^{33}$ ), wobei sich unterschiedliche Formen der Fremdheit überlagern. Nicht zu vernachlässigen ist die jüdische Herkunft der Autorin. Die zukünftige Elsa Triolet wächst als Tochter eines Moskauer Advokaten zwar unter privilegierten Bedingungen auf; dennoch prägt sie «[l]a question juive» ${ }^{34}$ («une véritable panique» bekennt die jugendliche Ėlla Kagan in ihrem Tagebuch angesichts der bevorstehenden Urteilsverkündung in der Affäre Beilis ${ }^{35}$ ). In ihrem Werk ist dezent, aber konstant das Motiv einer 〈jüdisch〉 codierten Fremdheit präsent, assoziiert mit «Weiblichkeit〉 als alternativer Figur des «internen Anderen». ${ }^{36}$ In Écoutez-voir erklärt sich Protagonistin Madeleine, «clocharde atypique» aus freien Stücken bzw. laut Eigendefinition stolze «rôdeuse», ${ }^{37}$ für «errante comme le Juif errant». ${ }^{38}$ Eben die «rôdeuse» erscheint bei Triolet nicht nur als gender-transgressive Gestalt, ${ }^{39}$ sondern auch als Modell «pulverisierter`Subjektivität ${ }^{40}$ in aller Ambivalenz: «Me voilà clocharde dans l'âme, cendres et poussière.» ${ }^{41}$

Ihr mehrfach marginaler Status verfolgt Triolet mitten im Erfolg: «[...] la dame Triolet est russe, juive et communiste. C'est un prix cousu de fil rouge», spottet Paul Léautaud, ${ }^{42}$ als sie 1945 für ihre Novellensammlung Le premier accroc coûte deux cents francs nachträglich den Prix Goncourt 1944 erhält. Aber auch später

31 Elsa Triolet: La Mise en mots. Genève: Albert Skira 1969 (Les Sentiers de la création), S. 98.

32 Leslee Poulton: The Influence of French Language and Culture in the Lives of Eight Women Writers of Russian Heritage. Lewiston u. a.: The Edwin Mellen Press 2002, S. 232.

33 Zit. nach Huguette Bouchardeau: Elsa Triolet, S. 7.

34 Lilly Marcou: Elsa Triolet, S. $12 \mathrm{f}$.

35 Zit. nach Huguette Bouchardeau: Elsa Triolet, S. 32.

36 Sigrid Weigel: 〈Frauen` und Juden〉 in Konstellationen der Modernisierung. Vorstellungen und Verkörperungen des «internen Anderen`. Ein Forschungsprogramm. In: Inge Stephan/Sabine Schilling/S. Weigel (Hg.): Jüdische Kultur und Weiblichkeit in der Moderne. Köln/Weimar/Wien: Böhlau 1994, S. 333-351; unter Bezugnahme auf das Konzept Tzvetan Todorovs (La Conquête de l'Amérique. La Question de l'autre. Paris: Seuil 1982).

37 Elsa Triolet: Écoutez-voir. Paris: Gallimard 1968, S. 117; vgl. auch S. $98 \mathrm{ff}$.

38 Ebda., S. 321; vgl. auch S. 276.

39 «Il serait plus juste de m'appeler une rôdeuse, bien qu'on n'emploie guère ce mot au féminin, étant donné que c'est un état rare chez la femme. On dit un rôdeur, une rôdeuse, ça ne se dit pas» (ebda., S. 117).

40 Vgl. Julia Kristeva: Étrangers à nous-mêmes. Paris: Gallimard 1991 [1988], S. 57: «Le cosmopolite heureux de l'être abrite dans la nuit de son errance une origine pulvérisée.»

41 Elsa Triolet: Écoutez-voir, S. 109.

42 Vgl. Pierre Assouline: Gaston Gallimard. Un demi-siècle d'édition française. Paris: Balland 1984, S. 392; zit. nach Unda Hörner: Das Romanwerk Elsa Triolets, S. 22. 
begleitet das Thema des Antisemitismus, den Olga Heller in Le Rendez-vous des étrangers für «la forme moderne du cannibalisme» erklärt, ${ }^{43}$ Triolets Biographie. Massiv holt sie die Problematik in den sechziger Jahren ein, als die sowjetische Literaturzeitschrift Ogonëk eine Verleumdungskampagne gegen Lilja Brik, angeblich Verbündete des 1938 exekutierten NKVD-Mannes Jakov Agranov und seiner «gang de sionistes», ${ }^{44}$ und Osip Brik als Repräsentanten einer «avant-garde antimarxiste» startet, denen die Schuld am Suizid Vladimir Majakovskijs zugeschrieben wird. ${ }^{45}$ "[...] quelqu'un est impatient de revenir au bon vieux temps des 〈cosmopolites〉 et des ‘assassins en blouses blanches〉. Lili n'est qu'un prétexte, les vraies raisons sont beaucoup plus profondes», kommentiert Triolet die antisemitische Stoßrichtung dieser Publikation - und kündigt ihre mit Aragon geplante Protestaktion in den Lettres françaises an, "parce que le combat contre l'antisémitisme est un devoir pour tout être honnête». ${ }^{46}$ Unter dem Titel «De la vérité historique» ${ }^{47}$ schreitet sie zur Gegenattacke gegen die «calomnie caractérisée» ${ }^{48}$ der Ogonëk-Autoren Vladimir Voroncov und Aleksandr Koloskov; ihre «Nouvelle réponse à Ogoniok» signieren auch Roman Jakobson und Léon Robel. ${ }^{49}$ Neben den Reaktionen Aragons und Triolets auf die Ereignisse in der Tschechoslowakei (die beide - im Gegensatz zum vernehmlichen Schweigen seitens Tel Quel unmissverständlich verurteilen ${ }^{50}$ ) war dieser Protest gegen den wieder erstarkenden Antisemitismus in der Sowjetunion auch ein - oft vernachlässigtes - Motiv für den folgenden Boykott der Lettres françaises. ${ }^{51}$ Unverblümt äußert Triolet in diesem Zusammenhang «son mépris pour ce qu'est devenu le régime soviétique, son désamour pour ce pays si cher». ${ }^{52}$

43 Elsa Triolet: Le Rendez-vous des étrangers, S. 360.

44 Zit. nach Marianne Delranc-Gaudric: Elsa Triolet, Maïakovski, Lili et Ossip Brik, Jakobson, Aragon... Une constellation créatrice (Les Lettres françaises, 1968). In: Recherches croisées Aragon/ Elsa Triolet 13 (2011), S. 83-91, hier S. 86.

45 Zit. nach Lilly Marcou: Elsa Triolet, S. 373.

46 Zit. nach Marianne Delranc-Gaudric: Elsa Triolet, Maïakovski, Lili et Ossip Brik, Jakobson, Aragon..., S. 86f.

47 Elsa Triolet in: Les Lettres françaises 1232 (2. Mai 1968); vgl. ebda., S. 86.

48 Zit. ebda.

49 Ebda., S. 88.

$50 \mathrm{Zu}$ den komplexen Relationen zwischen Aragon und Tel Quel vgl. Philippe Forest: Aragon/ Tel Quel. Un chassé-croisé. In: Recherches croisées Aragon/Elsa Triolet 11 (2007), S. 105-114.

51 Marianne Delranc-Gaudric: Elsa Triolet, Maïakovski, Lili et Ossip Brik, Jakobson, Aragon..., S. 90; vgl. auch Huguette Bouchardeau: Elsa Triolet, S. 350f.

52 Ebda., S. 351. 


\section{Migration und Mehrsprachigkeit: Zwischen «mal du pays» und «mal de la langue»}

Durchaus konfliktuell gestaltet sich also die Relation zum Herkunftsland; doch auch «[1]'amour que l'immigré peut avoir pour son pays d'adoption» bleibt «toujours un amour malheureux», wie Triolet schreibt. ${ }^{53}$ Auch wenn sie gelegentlich eine Pose affichierter Indifferenz bezieht (so in einer Passage, die sich wie ein Echo zu einem Exilgedicht Marina Cvetaevas liest: «Quant à moi, cela m'est égal, où vivre ${ }^{54}$ ), kultiviert Triolet jenen «mal du pays», der vor allem ein «mal de la langue» ist: «Ma langue maternelle, mon irremplaçable langue... Elle ne me servait plus à rien. Le mal de la langue est insupportable comme le mal du pays.» ${ }^{55}$

Der Sprachwechsel, den die bereits etablierte Autorin mit Bonsoir, Thérèse (1938) unternimmt, ${ }^{56}$ ist im russischen Emigrationsmilieu der ersten Welle alles andere als selbstverständlich, ja gilt manchen geradezu als 〈Verrat〉, ist die «vraie 〈patrie»» dieser Diaspora doch die russische Literatur. ${ }^{57}$ «Pour gagner de l'argent, Merejkovski se met parfois à écrire en français. Moi-même il m'arrive de sombrer dans cette déchéance absurde», gesteht Zinaida Gippius. ${ }^{58}$ "Attirée par le français, je me croyais encore, à cette époque, obligée d'écrire dans ma langue maternelle - en fait, depuis longtemps je pensais en français», erinnert sich Zoé Oldenbourg, die ihren «bilinguisme» wie Triolet als «à la fois un avantage et un handicap» betrachtet. ${ }^{59}$ Letztere reflektiert ihren «bi-destin» bzw. «demi-destin»,

53 Elsa Triolet: Préface au mal du pays. In: Euvres romanesques croisées d'Elsa Triolet et Aragon. Bd. 27: Le Rendez-vous des étrangers. Paris: Laffont 1967, S. 12; zit. nach Lilly Marcou: Elsa Triolet, S. 322.

54 Zit. nach Huguette Bouchardeau: Elsa Triolet, S. 72; vgl. dazu Marina Cvetaeva: Toska po rodine! Davno... [1934]. In: Stichotvorenija. Poèmy. Moj Puškin. Moskva: Olma 2000, S. 280-281.

55 Elsa Triolet: Ouverture, S. 26.

56 Vgl. Marianne Delranc-Gaudric: D’Эльза Триоле à Elsa Triolet. Les quatre premiers romans d'Elsa Triolet et le passage du russe au français. Diss., Paris: INALCO 1991.

57 Georges Nivat: Russie-Europe. La Fin du schisme. Études littéraires et politiques. Lausanne: L'Âge d'Homme 1993, S. 656. «In emigration, literature became even more crucial to the émigrés' collective identity, for language is the most obvious sign of belonging to a specific group. The Russian language, both written and oral, bound the émigrés together despite their geographic dispersion», betont auch Marc Raeff: «For this reason, too, the cultural life and creativity of Russia Abroad was preeminently, if not exclusively, verbal» (Russia Abroad, S. 10f.).

58 Zit. nach Leslee Poulton: The Influence of French Language and Culture, S. 202.

59 Zoé Oldenbourg: Visages d'un autoportrait. Paris: Gallimard 1977, S. 280, 295. 
ihren «destin traduit» als zweisprachige Schriftstellerin auf poetologischer MetaEbene, ${ }^{60}$ zwischen Valorisierung kultureller Vielfalt und Selbstpathologisierung:

Être bilingue comme je le suis est une anomalie. Comme d'être daltonien ou gaucher, avoir un seul œil au milieu du front, six doigts à une main, être l'une des deux sœurs siamoises. Ne croyez pas que parler indifféremment la langue de deux pays vous donne deux patries, cela vous rend au contraire deux fois étrangère: étrange que vous ayez quitté un pays, étrange que vous soyez allée et restée ailleurs. ${ }^{61}$

«En grinçant des dents, en m’arrachant les cheveux», zitiert sie ihre eigene Reaktion auf Ivan Bunins Frage: «Comment [...] avez-vous pu abandonner, trahir votre langue? Comment?» ${ }^{62}$ In der Tat ist der Sprachwechsel für Triolet im Gegensatz zu Oldenbourg, aber etwa auch Nathalie Sarraute oder Irène Némirovsky, die von früher Kindheit an auf Französisch erzogen werden - eine Herausforderung. ${ }^{63}$ In drastischen körperlichen Begriffen evoziert sie die Arbeit an ihrem ersten französischsprachigen Werk, das sie auf Russisch zu schreiben beginnt, um sich selbst mühselig - «je suis difficile à traduire, aussi bien du français en russe que du russe en français» ${ }^{64}$ - ins Französische zu übersetzen: ${ }^{65}$ "J'en souffrais physiquement, comme si on m'avait mis un corset de plâtre.» ${ }^{66}$

Warum diese Quälerei, nachdem Triolet, von Viktor Šklovskij und Gor'kij höchstpersönlich unterstützt, schon mehrere Texte auf Russisch publiziert hatte? Nachdem Na Taiti/À Tahiti (1925) und Zemljanička/Fraise-des-Bois (1926) recht gut angekommen waren, wird Zaščitnyj cvet/Camouflage (1928) von der Kritik kühl

60 Elsa Triolet: La Mise en mots, S. 8; vgl. dazu auch Léon Robel: Un destin traduit. La Mise en mots d'Elsa Triolet. In: Marianne Gaudric-Delranc (Hg.): Elsa Triolet. Un écrivain dans le siècle, S. 19-32.

61 Elsa Triolet: Préface au mal du pays; zit. nach Huguette Bouchardeau: Elsa Triolet, S. 132.

62 Elsa Triolet: Préface au mal du pays, S. 15; zit. nach Lilly Marcou: Elsa Triolet, S. 147. «J'ai connu Ivan Bounine, le Prix Nobel de littérature, l'émigré russe... je lui ai demandé comment il pouvait écrire en russe, vivant en France», berichtet eine Figur in Le Rendez-vous des étrangers. «Il m'a répondu qu'il pouvait! Pour lui, la patrie d'un homme était sa langue, et un écrivain n'abandonnait sa patrie que le jour où il abandonnait sa langue. Ceci, contre les écrivains russes émigrés qui écrivent en français» (ebda., S. 312f.).

63 Leslee Poulton: The Influence of French Language and Culture, S. 240.

64 Elsa Triolet: Ouverture, S. 22.

65 Zur Problematik der Selbstübersetzung zweisprachiger franko-russischer Autor^innen (darunter Elsa Triolet) vgl. Anna Lushenkova Foscolo: Les écrivains de langue russe en exil. Plurilinguisme et autotraduction. In: Martina Stemberger/Lioudmila Chvedova (Hg.): Littératures croisées. La langue de l'autre. Fragments d'un polylogue franco-russe (XXe-XXI $I^{e}$ siècles). Nancy: PUN - Éditions Universitaires de Lorraine 2017, S. 179-192.

66 Elsa Triolet: Ouverture, S. 32. 
aufgenommen. ${ }^{67}$ Ihr letztes gänzlich auf Russisch verfasstes Werk, Busy, von einem «point de vue ethnographique» angelegte Schilderung der Pariser Modewelt für ein russisches Publikum, ${ }^{68}$ erscheint nur mehr in Auszügen in Krasnaja nov' (1933) und verschwindet darauf trotz Gor'kijs Intervention im Nirwana der Zensur. ${ }^{69}$

«[...] c'est l'interdiction de Colliers qui devait amener Elsa à franchir le pas d'une langue à l'autre et à écrire pour nous, Français», erklärt Aragon. ${ }^{70}$ Triolet ist eine stark rezeptionsorientierte Autorin; da ihr nun die sowjetische Leserschaft abhandenkommt und sie von vornherein nicht für die russische Emigration schreibt, drängt sich der Wechsel der Literatursprache auf:

On croirait qu'une langue, personne ne peut vous la prendre, que vous l'emportez avec vous où que vous alliez [...]... En réalité, une langue cela se partage avec un peuple, un pays, vous ne pouvez la conserver au fond de vous-même, il faut qu'elle s'exerce, il faut s'en servir, sans quoi elle se rouille, s'atrophie et meurt. ${ }^{71}$

Dazu kommt die persönliche Dimension, Triolets Bestreben, aus der ambivalenten Rolle als Muse, ihrer «position en retrait: avec Aragon, derrière Aragon, pour Aragon» ${ }^{72}$ auszubrechen: "Et quand j'ai recommencé à écrire, c'était contre toi, avec rage et désespoir, parce que tu ne me faisais pas confiance», präzisiert sie in ihrer «Ouverture» zu den Euvres romanesques croisées. ${ }^{73}$

Triolet definiert sich in der Folge nicht einfach als französische Schriftstellerin, sondern als «une Russe qui écrit en français» ${ }^{74}$ - und bewahrt auch sprachlich die Spur ihrer fremden Herkunft: «J'aurais pu me faire passer mon accent russe. J'ai préféré le garder. J'écris avec mon authentique accent, il est dans le caractère de mon écriture, dans mon style, dans ma folie elle-même: la folie aussi a une nationalité.» ${ }^{75}$

67 Vgl. Marianne Delranc-Gaudric: L'accueil critique des premiers romans d'Elsa Triolet en Union soviétique. In: Recherches croisées Aragon/Elsa Triolet 6 (1998), S. 13-36.

68 Zit. nach Huguette Bouchardeau: Elsa Triolet, S. 112.

69 Elsa Triolet: Ouverture, S. 30; vgl. auch Lilly Marcou: Elsa Triolet, S. 109.

70 Aragon: Préambule. In: Euvres romanesques croisées d'Elsa Triolet et Aragon. Bd. 39: Fraisedes-Bois. Camouflage. Paris: Laffont 1973, S. V; zit. nach Antonín Měšłan: Elsa Triolet in der russischen Literatur. In: Wiener Slawistischer Almanach Bd. 14 (1984), S. 153-165, hier S. 158.

71 Elsa Triolet: Ouverture, S. 26.

72 Lilly Marcou: Elsa Triolet, S. 158.

73 Elsa Triolet: Ouverture, S. 31.

74 Elsa Triolet: Préface au mal du pays, S. 15; zit. nach Lilly Marcou: Elsa Triolet, S. 323. Bezeichnenderweise reagiert Triolet später verärgert darauf, dass die sowjetische Kritik ihre Vorgeschichte als russische Schriftstellerin ignoriert, «comme si je n'avais jamais écrit de livres russes» (zit. nach Tamara Balachova: Le double destin d'Elsa Triolet en Russie, S. 97).

75 Elsa Triolet: La Mise en mots, S. 56; vgl. auch dies.: Ouverture, S. 27. 
Doch nicht nur um die Migration von Personen geht es hier, sondern auch um jene von Theorien und Kunstwerken: Triolet ist eine zentrale Vermittlerfigur der russischen Avantgarde und des russischen Formalismus in Frankreich. Avantgarde, das bedeutet bei und für Triolet wesentlich Vladimir Majakovskij, Vorbild hinsichtlich einer «posture», die künstlerisches und politisches Engagement verbindet. $^{76}$ "[P]as peu fière d'avoir une des premières senti le génie de Maïakovski», ${ }^{77}$ fungiert sie während der Paris-Aufenthalte des Dichters in den zwanziger Jahren als seine Vermittlerin und Dolmetscherin; unermüdlich betätigt sie sich nach seinem Tod als seine französische Übersetzerin, Biographin und Popularisatorin. «[...] je porte en moi la plaie ouverte du suicide de Maïakovski [...]», ${ }^{78}$ schreibt sie noch viele Jahre später über ihren ersten literarischen «mentor» ${ }^{79}$ (und Modell - über Gender-Grenzen hinweg - mehrerer fiktiver Figuren in ihrem Werk), posthum ihre Stütze in diversen querelles: «Heureusement que j'ai à côté de moi, pour me soutenir, Maïakovski. Il est là, il me dit: «Te rappelles-tu encore du manifeste: La Gifle au goût public? Vas-y!ı» ${ }^{80}$

Den Versuch, Majakovskij ins Französische zu übertragen, wagt Triolet bereits während ihrer Zeit auf Tahiti, ${ }^{81}$ in einer Situation gleich mehrfacher Ver- und Entfremdung. Ihrerseits eine «Exotin〉 für die polynesischen Einheimischen, ${ }^{82}$ bemüht sie sich (vergeblich), ihrem Mann Russisch beizubringen und mit ihm Majakovskij zu übersetzen. ${ }^{83} 1930$ arbeitet sie an der Übertragung einiger Majakovskij-Gedichte für die erste Nummer des Surréalisme au service de la Révolution (wobei sie mit dem Resultat höchst unzufrieden ist). ${ }^{84}$ Majakovskij übersetzt sie

76 Huguette Bouchardeau: Elsa Triolet, S. 193.

77 Elsa Triolet: Ouverture, S. 18.

78 Elsa Triolet: Préface à La Lutte avec l'ange [1965]. In: Le Monument. Paris: Gallimard 1976 [1957], S. 7-22, hier S. 16. Der hier zitierte Essay La Lutte avec l'ange, «une sorte de réponse collective aux critiques parues dans la presse, aux lettres par moi reçues [...] ainsi qu'aux discussions privées et publiques concernant Le Monument» (Le Monument, S. 205 [Appendices]), erscheint am 5. September 1957 in Les Lettres françaises; an diesen Text knüpft die «Préface à La Lutte avec l'ange» im Bd. 14 (Le Monument) der Euvres romanesques croisées d'Elsa Triolet et Aragon (Paris: Laffont 1965) an.

79 Huguette Bouchardeau: Elsa Triolet, S. 47.

80 Elsa Triolet: Maïakovski et nous. Pour le dix-septième anniversaire de la mort de Vladimir Maïakovski [1947]. In: L'Écrivain et le livre ou La Suite dans les idées. Bruxelles: Aden/Société des Amis de Louis Aragon et Elsa Triolet 2012 [1948], S. 25-80, hier S. 79.

81 Vgl. Leslee Poulton: The Influence of French Language and Culture, S. 176.

82 Ebda., S. 230.

83 Vgl. Lilly Marcou: Elsa Triolet, S. 48; Huguette Bouchardeau: Elsa Triolet, S. 58.

84 Vgl. Huguette Bouchardeau: Elsa Triolet, S. 114. 
weiterhin mit besonderem Engagement, ${ }^{85}$ daneben aber auch Marina Cvetaeva, ${ }^{86}$ Viktor Šklovskij, Anna Achmatova, Velimir Chlebnikov, Sergej Esenin sowie russische Klassiker, Gogol' und Čechov. ${ }^{87} 1965$ gibt sie die zweisprachige Anthologie La Poésie russe bei Seghers heraus; in umgekehrter Richtung übersetzt sie neben Aragon und André Gide auch Célines Voyage au bout de la nuit. ${ }^{88}$

Triolet reflektiert die Übersetzung als «une forme particulière de création, pleine de responsabilité et d'abnégation, qui n'apporte au traducteur ni gloire ni argent (s'il n'est pas un bousilleur)». ${ }^{89}$ Bei allen Klagen über die Mühen der translatorischen 〈Falschmünzerei ${ }^{90}$ fungiert diese für sie auch als «une sorte de tremplin d'une langue à l'autre», ${ }^{91}$ Instrument literarischer Identitätsfindung bzw. -stiftung. ${ }^{92}$

\section{Avantgarde und Gender: Von Musen und «grands poètes»}

«Elle a eu le mérite d'être dans le sillage de grands poètes», so Henriette Nizans zweifelhaftes Kompliment. ${ }^{93}$ Zahlreiche Äußerungen im Lauf der Jahre zeugen davon, dass Triolet mit dem ihr zugeschriebenen (zugleich freilich selbst provozierten und perpetuierten) Status als «Ikone, Muse, Verführerin» ${ }^{94}$ nicht allzu

85 «Je traduis avec tant d'amour, je souffre tant pour chaque vers défiguré par la traduction que c'est comme si je marchais avec des chaussures trop petites qui me serreraient de façon insupportable. Personne ne fera mieux, mais vraiment, «quelle saloperie, la traduction`» (Elsa Triolet an Lilja Brik, August 1955; zit. nach Huguette Bouchardeau: Elsa Triolet, S. 254). [Aus praktischen Gründen wird die Korrespondenz Triolet/Brik hier und im Folgenden in frz. Übersetzung zitiert.]

86 Vgl. Marina Tsvétaeva: Poèmes. Traduits par Elsa Triolet. Paris: Gallimard 1968.

87 Vgl. auch Elsa Triolets Histoire d'Anton Tchekhov. Sa vie, son œuvre (Paris: Éd. français réunis 1954), die im Gegensatz zu ihren Übersetzungen sehr positiv aufgenommen und zum Leidwesen der Autorin auch sogleich plagiiert wird (Huguette Bouchardeau: Elsa Triolet, S. 256).

88 Vgl. Lilly Marcou: Elsa Triolet, S. 143.

89 Elsa Triolet an Lilja Brik, 1968; zit. nach Huguette Bouchardeau: Elsa Triolet, S. 311.

90 «La traduction devrait être l'imitation d'un texte écrit dans une autre langue; il faut y apporter le soin du faux-monnayeur à imiter un billet de banque» (Elsa Triolet: La Mise en mots, S. 90).

91 Lilly Marcou: Elsa Triolet, S. 142.

92 Vgl. Monica Biasiolo: Écrire dans (et avec) la langue de l'autre. Elsa Triolet et Vladimir Maïakovski entre biographie et textes. In: Thomas Stauder (Hg.): L'identité féminine dans l'œuvre d'Elsa Triolet, S. 59-80, hier S. 64.

93 Henriette Nizan/Marie-José Jaubert: Libres mémoires. Paris: Laffont 1989, S. 196; zit. nach Unda Hörner: Das Romanwerk Elsa Triolets, S. 20.

94 Anja Tippner: «Aller et retour...», S. 118. 
glücklich ist. «Une femme posée sur un piédestal n’est pas forcément heureuse», erklärt sie Pierre Daix. ${ }^{95}$

Mit diversen «grands poètes», deren Weg sie kreuzt, unterhält Triolet nicht immer harmonische Beziehungen; ihr widersprüchliches Verhältnis zur Pariser Avantgarde ist auch unter dem Gender-Aspekt zu betrachten. ${ }^{96}$ Kaum zufällig gehört dem Kreis der Surrealisten zur Zeit seiner Hochblüte keine einzige Frau an - erst in der Spätphase spielen Frauen, darunter auffallend viele NichtFranzösinnen, eine Rolle. ${ }^{97}$ Die Avantgarde formiert sich wesentlich als «männliche Aufbruchs- und Oppositionsbewegung»; ${ }^{98}$ unter Aufrechterhaltung oder sogar Verstärkung der «bürgerlichen symbolischen Kodierungen» bedienen sich «die Leitfiguren der verschiedenen Avantgarden» des 20. Jahrhunderts, von Marinetti bis Breton, «eines maskulinen Codes». ${ }^{99}$ Die im Rahmen der surrealistischen Ästhetik für jenes enigmatische Andere «Frau〉 vorgesehenen Funktionen Muse und Medium, «Projektionsfläche» ${ }^{100}$ und «Poesie-Erreger» bzw. «DifferenzErreger» (wie Gisela Febel Hans Bellmers Formel variiert) ${ }^{101}$ - werden auch den «realen Frauen der Surrealisten» ${ }^{102}$ zugeschrieben. ${ }^{103}$ In diesem Sinne stellt

95 Zit. nach Lilly Marcou: Elsa Triolet, S. 343 (unter Verweis auf ein Gespräch mit Pierre Daix, 21. Jänner 1993).

96 Zur komplexen Frage nach Triolets in mancher Hinsicht ambivalentem 〈Feminismus〉 vgl. Loukia Efthymiou: Genre, discours et engagement chez Elsa Triolet. In: Thomas Stauder (Hg.): L'identité féminine dans l'œuvre d'Elsa Triolet, S. 223-235. «Observatrice perspicace de la société sexuée de son temps» (S. 223), verwahrt Triolet sich gegen jede künstliche Geschlechtertrennung, auch und vor allem in Form der berüchtigten 〈Frauenliteratur»: «Il n’y a pas raison apparente à ce fait [...] qu'on a mis ensemble toutes les femmes qui écrivent [...] et à l'écart des hommes, comme dans un harem ou dans une synagogue» (zit. ebda., S. 225). Wie Alain Trouvé betont, ist «la question de l'identité féminine» bei Triolet stets auch im Kontext ihrer «double origine russe et juive» und der damit assoziierten «questions de la langue et de la culture» zu sehen. Ders.: Roman et différence sexuelle chez Elsa Triolet et Aragon. In: Thomas Stauder (Hg.): L'identité féminine dans l'œuvre d'Elsa Triolet, S. 99-119, hier S. 100.

97 Vgl. Susan Rubin Suleiman: Subversive Intent, S. 11ff. («A Double Margin. Women Writers and the Avant-Garde in France»), hier insbes. S. 29ff.

98 Inge Stephan: Zwischen Provinz und Metropole. Zur Avantgarde-Kritik von Marieluise Fleißer. In: I. Stephan/Sigrid Weigel (Hg.): Weiblichkeit und Avantgarde. Berlin/Hamburg: Argument 1987, S. 112-132, hier S. 117.

99 Gisela Febel: «Poesie-Erreger» oder von der signifikanten Abwesenheit der Frau in den Manifesten der Avantgarde. In: Wolfgang Asholt/Walter Fähnders (Hg.): «Die ganze Welt ist eine Manifestation», S. 81-108, hier S. 81ff.

100 Ebda., S. 95.

101 Ebda., S. 100.

102 Vgl. Unda Hörner: Die realen Frauen der Surrealisten. Simone Breton, Gala Éluard, Elsa Triolet. Frankfurt a.M.: Suhrkamp 1998.

103 Vgl. Gisela Febel: «Poesie-Erreger» oder von der signifikanten Abwesenheit der Frau, S. 95ff. 
Triolets theoretische Auseinandersetzung mit der Avantgarde per se bereits eine gewisse Transgression dar. ${ }^{104}$

«[E]lle supportait mal les impératifs du milieu surréaliste», bemerkt Aragon über seine Gefährtin. ${ }^{105}$ Bekannt ist die Antipathie, die sie mit André Breton verbindet $^{106}$ («Que le diable l'emporte», schreibt Triolet noch 1948 an ihre Schwester ${ }^{107}$ ). Während Breton sich für die Produktion Gisèle Prassinos’, damals gerade ein Teenager, begeistert ${ }^{108}$ und mit seiner Poetik des amour fou im Grunde «ein Modell der 〈Junggesellenerotik»» kultiviert, ${ }^{109}$ weiß er mit der gleichaltrigen, scharfsichtigen und -züngigen Triolet («[u]ne épée aux yeux bleus», so Pablo Nerudas berühmte Formel ${ }^{110}$ ) nichts anzufangen und wirft ihr vor, Aragon den Surrealisten entfremdet zu haben. Turbulent verläuft auch ihre kurze Liaison mit dem zu jener Zeit ebenfalls den Surrealisten nahestehenden Marc Chadourne, ${ }^{111}$ verarbeitet in Camouflage. ${ }^{112}$ Kurz: De facto habe, so Bouchardeau, Triolet nur «de très loin» an den Aktivitäten der Surrealisten partizipiert. ${ }^{113}$

104 «Selten genug ist, daß sich eine Frau mit der Avantgarde auf einer theoretischen Ebene auseinandersetzt und dies auf eine sehr rationale Art und Weise», wie Unda Hörner kommentiert (Das Romanwerk Elsa Triolets, S. 166).

105 Aragon parle avec Dominique Arban. Paris: Seghers 1968, S. 96; zit. nach Lilly Marcou: Elsa Triolet, S. 114.

106 Vgl. Susanne Nadolny: Elsa Triolet (1896-1970). Glückssuche an der Schreibmaschine. In: Dies. (Hg.): Gelebte Sehnsucht. Grenzgängerinnen der Moderne. Berlin: Ebersbach 2005, S. 149175, hier S. $164 \mathrm{f}$.

107 Elsa Triolet an Lilja Brik, 3. Mai 1948; zit. nach Lilly Marcou: Elsa Triolet, S. 95.

108 Vgl. Gisela Febel: «Poesie-Erreger» oder von der signifikanten Abwesenheit der Frau, S. 96.

109 Sigrid Weigel: Hans Bellmer Unica Zürn. Junggesellenmaschinen und die Magie des Imaginären. In: Inge Stephan/S. Weigel (Hg.): Weiblichkeit und Avantgarde, S. 187-230, hier S. 207; unter Verweis auf Günter Metken (Hg.): Als die Surrealisten noch recht hatten. Texte und Dokumente. Hofheim: Wolke 1983 [1976], S. 13.

110 Vgl. Pablo Nerudas Nachruf auf «Notre amie» (Europe, Juni 1971); zit. nach Lilly Marcou: Elsa Triolet, S. 385.

111 Vgl. ebda., S. 77f.; Huguette Bouchardeau: Elsa Triolet, S. 89ff.

112 «Sur cet amour, voyez Camouflage, je ne saurais en parler mieux», erklärt Triolet (Journal, 22. September 1928; zit. nach Huguette Bouchardeau: Elsa Triolet, S. 91). Marc Chadourne liefert in Vasco, seinem bekanntesten, u. U. auch von Triolets Tahiti-Text beeinflussten Roman, eine wenig schmeichelhafte Charakteristik seiner transparent fiktionalisierten Ex-Geliebten: Der Protagonist erinnert sich an «[u]ne Juive russe que j'avais, un soir, ramenée du Dôme... Raya! Vingt ans, pas laide, belle même, mais disgracieuse, gracile avec des jambes lourdes, tendre avec maladresse, des yeux méchants d'inquiétude dans une figure de chagrin, un peu voûtée. Un air esclave et rancunier de porteuse de fardeaux pour Juif errant. Elle eut tôt fait de se cramponner à moi, à mon appartement, à ma vie avec une obstination de bête perdue» (Vasco. Paris: Plon 1927, S. 42f.).

113 Huguette Bouchardeau: Elsa Triolet, S. 114. 


\section{Avantgarde und Genre: Poetischer Realismus, Medialität, Montage}

Komplexer ist ihr poetisches Verhältnis zum Surrealismus. ${ }^{114}$ Den Prinzipien der russischen Avantgarde und insbesondere Majakovskijs treu, insistiert Triolet auf der Bedeutung des 〈Handwerks〉; in ihrer ästhetischen Summa La Mise en mots (1969) setzt sie der écriture automatique eine Technik der «volonté» und der «concentration» entgegen:

$\mathrm{Au}$ contraire de l'écriture automatique qui essaye d'éliminer la conscience, de libérer l'inconscient, c'est une concentration si intense sur la chose à exprimer, qu'elle vous fait deviner le numéro gagnant à la roulette: si j'avais assez de volonté, de force de concentration, j'arriverais à tous les coups gagnante dans l'affaire de l'écriture. C'est, entre le langage et moi, une perpétuelle dispute. ${ }^{115}$

Andererseits bekennt sie sich zu einer profunden Affinität zum surrealistischen Text; ihren Wunsch, Aragon kennenzulernen, motiviert sie mit ihrer Lektüre des Paysan de Paris: «[...] parce que rien ne pouvait m'être plus proche, plus mien, plus parent comme on dit en russe [...]»; ${ }^{116}$ signifikant ihre doppelte kulturelle Codierung dieser Sympathie durch den Verweis auf den entsprechenden russischen Ausdruck (rodnoe), mit dem mythisch überhöhte Liebesbeziehung und «mal du pays» kurzgeschlossen werden.

Wie weit hat diese Ästhetik also ihr eigenes Schaffen (mit-)geprägt? Wiederholt wurde die Diskrepanz zwischen Triolets Engagement für das Werk einer Reihe avantgardistischer Künstler und ihrer Entscheidung für eine tendenziell un-avantgardistische Schreibweise betont, der in diesem Fall besonders markante «Bruch zwischen Form und der inhaltlichen, stark kommentierten Vermittlung eines formalen Ideals». ${ }^{117}$

Neben der Gender- stellt sich die Genre-Frage: Ist die privilegierte avantgardistische Domäne die Lyrik, daneben Drama und Performance, nur sekundär auch narrative Prosa, so versagt Triolet, Schlüsselfigur der Popularisierung moderner russischer Dichtung in Frankreich, sich die lyrische Produktion: «[...] rien de ce que j'écris ne s'organise, ne s'ordonne jamais en vers. [...] Je parle pour dire.

114 Vgl. Alain Trouvé: La Lumière noire d'Elsa Triolet, S. 11.

115 Elsa Triolet: La Mise en mots, S. 56.

116 Elsa Triolet: Ouverture, S. 27.

117 Unda Hörner: Das Romanwerk Elsa Triolets, S. 76. 
[...] non, je n'ai pas accès au vers [...].» ${ }^{118}$ (Nach-)dichterisch betätigt sie sich exklusiv als Übersetzerin - und formuliert dafür ein Idealpostulat, das mit ihrer eigenen Abstinenz kontrastiert: «Les conditions idéales d'une traduction de la poésie seraient qu'un grand poète traduise un autre grand poète qu'il aurait lu dans l'original et pour lequel il se serait pris de passion.» ${ }^{119}$ Sie lässt ihre lyrische Kreativität allerdings in ihre Prosa einfließen, die so einen spezifischen «réalisme poétique» entfaltet. $^{120}$

In ihrem Euvre sind auch avantgardistische Aspekte präsent, angefangen mit dem Montageroman Bonsoir, Thérèse (in den Augen der Autorin kein «roman»wie das Werk auf Wunsch des Herausgebers Denoël etikettiert wurde -, sondern «une suite de nouvelles vaguement reliées entre elles» ${ }^{121}$ ), den Jean-Paul Sartre positiv rezensiert und Paul Nizan in seine Sammlung Pour une nouvelle culture (1939) aufnimmt. ${ }^{122}$ Im ersten Band der Euvres romanesques croisées wird dieser Text, der eine auch - und sei es im Modus kritischer Auseinandersetzung - surrealistisch inspirierte Traumpoetik entspinnt, von Max Ernst illustriert. ${ }^{123}$ Trouvé situiert Triolet sehr wohl auch im Kontext der «expériences narratives des surréalistes» ${ }^{124}$ (sowie - in Bezug auf die Trilogie L'Âge de nylon [1959/1963] und Les Manigances [1962] - des Nouveau Roman und der Dekonstruktion ${ }^{125}$ ).

Ihr Konzept der Collage erläutert Triolet anhand diverser intermedialer Referenzen, vom «faux-semblant» der Schlösser Ludwigs II. bis zu Godard und

118 Elsa Triolet: La Mise en mots, S. 57f., 60. Nicht nur in Bezug auf ihre angebliche lyrische Talentlosigkeit frappiert in Triolets Diskurs das Moment chronischer Selbstzweifel: «Je ne suis pas un écrivain [...] je suis simplement une femme malheureuse et j'écris avec mon malheur», heißt es in ihrem Tagebuch am 29. September 1924 (zit. nach Lilly Marcou: Elsa Triolet, S. 66); an anderer Stelle: «Je suis extraordinairement dénuée d'idées, je n'écrirai jamais rien de convenable [...]» (zit. nach Huguette Bouchardeau: Elsa Triolet, S. 82), oder auch: «[...] je ne suis pas une romancière. Mes moyens sont petits, petits... [...] Le mal profond est dans ce que j'ai perdu mon pays et ma langue et que maintenant je suis là à ne rien connaître organiquement. Sauf moi-même. Alors il s'agit sans fin de moi-même» (Journal, 1. September 1938; zit. nach Huguette Bouchardeau: Elsa Triolet, S. 133; Lilly Marcou: Elsa Triolet, S. 216) - womit kreative Krise, Migrations- und Sprachwechselproblematik wiederum assoziiert werden.

119 Elsa Triolet: L'Art de traduire [Vorwort zu La Poésie russe. Paris: Seghers 1965]; zit. nach Huguette Bouchardeau: Elsa Triolet, S. 313.

120 Alain Trouvé: Roman et différence sexuelle chez Elsa Triolet et Aragon, S. 115; vgl. auch ders.: La Lumière noire d'Elsa Triolet, S. $12 \mathrm{f}$.

121 Elsa Triolet: La Mise en mots, S. 99.

122 Vgl. Unda Hörner: Das Romanwerk Elsa Triolets, S. 21.

123 Vgl. Elsa Triolet: Bonsoir, Thérèse. In: Euvres romanesques croisées d'Elsa Triolet et Aragon. Bd. 1. Paris: Laffont 1964, S. 145-292.

124 Alain Trouvé: La Lumière noire d'Elsa Triolet, S. 195.

125 Ebda., S. 197. 
Picasso. ${ }^{126}$ Allgemein ist das Werk dieser Autorin, die als Tochter einer quasiprofessionellen Pianistin in einer «maison de musique» aufwächst, ${ }^{127}$ selbst Architektur studiert ${ }^{128}$ und sich in ihren journalistischen Texten kenntnisreich auch mit bildender Kunst beschäftigt, ${ }^{129}$ in seiner inter- und metamedialen Dimension von Interesse, der permanenten Reflexion und Exposition künstlerischer Mittel und Stile als solcher - auch dies ja ein eminent avantgardistischer Zug. ${ }^{130}$

«Ah! ce que je l'enviais, ce bonheur de cinéma!...», ruft die Erzählerin von Bonsoir, Thérèse beim Anblick eines Liebespaars aus. ${ }^{131}$ Mit sfilmischen` Schreibweisen experimentiert Triolet, die sich auch im Genre Drehbuch erprobt und an einem franko-sowjetischen Kinoprojekt mitwirkt, ${ }^{132}$ bereits in ebendiesem Text; der Film fungiert auch als Vorbild hinsichtlich der potentiellen Versöhnung von «Popularität und avantgardistische[r] Form». ${ }^{133}$ Auch Musik partizipiert an dieser strategisch auf die Krise des Buches reagierenden «Medialisierung der Literatur». ${ }^{134}$ Als «éléments préfabriqués» ${ }^{135}$ integriert Triolet Chanson-Zitate in fast sämtliche Romane; ${ }^{136}$ einer limitierten Edition von Le Rendez-vous des étrangers wird zusätzlich zu den im Text enthaltenen Noten ${ }^{137}$ eine Schallplatte mit Michail Svetlovs von Joseph Kosma vertonter Ballade Granada (1926) beigelegt ${ }^{138}$ - auf dem Weg intermedialer Fusion gelingt punktuell die kosmopolitische Synthese.

126 Elsa Triolet: Préface au désenchantement. In: Euvres romanesques croisées d'Elsa Triolet et Aragon. Bd. 9: Anne-Marie (1). Paris: Laffont 1965; zit. nach Huguette Bouchardeau: Elsa Triolet, S. 157.

127 Elsa Triolet: Souvenirs sur Maïakovski. In: Maïakovski. Vers et proses. Paris: Éd. français réunis 1957; zit. nach Huguette Bouchardeau: Elsa Triolet, S. 14; vgl. auch Lilly Marcou: Elsa Triolet, S. 15.

128 Vgl. Huguette Bouchardeau: Elsa Triolet, S. 24.

129 Es ist etwa Triolet, die Pavel Fedotov, «ce grand peintre méconnu en France», mit ihrer Übersetzung von Viktor Šklovskijs Kapitan Fedotov aus dem Jahr 1936 bzw. einem ausführlichen Beitrag in den Lettres françaises (23. September 1948) bekannt macht. Vgl. Maryse Vassevière: Aragon, Breton et la peinture soviétique. In: Recherches croisées Aragon/Elsa Triolet 13 (2011), S. 95-119, hier S. 100.

130 Vgl. Peter Bürger: Theorie der Avantgarde. Frankfurt a. M.: Suhrkamp 1974, S. 23.

131 Elsa Triolet: Bonsoir, Thérèse, S. 220.

132 Vgl. die franko-sowjetische Produktion Normandie-Niémen bzw. Normandija-Neman (1960; Regie: Jean Dréville/Damir Vjatič-Berežnych); dazu Huguette Bouchardeau: Elsa Triolet, S. 281ff.

133 Unda Hörner: Das Romanwerk Elsa Triolets, S. 124.

134 Ebda., S. 136.

135 Vgl. Elsa Triolets Definition in Le Cheval blanc. Paris: Gallimard 1972 [1943], S. 25; zit. nach Unda Hörner: Das Romanwerk Elsa Triolets, S. 70.

136 Ebda., S. 134.

137 Vgl. Elsa Triolet: Le Rendez-vous des étrangers, S. 416f.

138 Vgl. Unda Hörner: Das Romanwerk Elsa Triolets, S. $135 f$. 
Triolet liebäugelt mit Perspektiven des «texte-image», des «texte-musique», mit der Idee eines Musik-Romans «Opéra». ${ }^{139}$ Realisiert wird ihr Projekt eines «roman imagé». ${ }^{140} 1968$ erscheint Écoutez-voir, ${ }^{141}$ samt Instruktion zur «lecture simultanée, à la façon des bandes dessinées»: «NE REGARDEZ PAS LES IMAGES QUI SUIVENT SANS LIRE LE TEXTE: L'Un NE VA PAS SANS L'AUtRe.» ${ }^{142}$ Von Seite zu Seite wiederholt sich in diesem Werk, das Triolet schon mit ihrem Chlebnikov-Motto auch in der Tradition der russischen Avantgarde situiert, der verfremdende Fiktionsbruch.

Aber auch abseits dieses experimentellen Romans mit seiner Fülle heterogener «citations picturales» ${ }^{143}$ aus Bildhauerkunst, Malerei, Fotografie und Alltag arbeitet Triolet mit der Materialität des Buches. La Mise en mots, Versuch einer «écriture audiovisuelle», ${ }^{144}$ inszeniert die Fortsetzung der Literatur mit anderen Mitteln: «À Bout D’ARguments verbaux» wendet die Autorin sich «vers l'image». ${ }^{145}$ Elizabeth Klosty Beaujour interpretiert Triolets intermediale écriture auch als spezifische Form literarischer «Zweisprachigkeit», Kompensationsstrategie angesichts der «intimate separation of bilingualism». ${ }^{146}$ In Le rossignol se tait à l'aube (1970), «[1]ivre-miroir, livre-testament», ${ }^{147}$ werden unterschiedliche Schriftfarben zur Differenzierung zwischen diegetischer Realität und Traumerzählung eingesetzt. $^{148}$

139 Elsa Triolet: La Mise en mots, S. 115ff.

140 Ebda., S. $106 \mathrm{ff}$.

141 Den Titel Écouter Voir trägt die von Michel Apel-Muller organisierte, am 28. April 1972 in Marseille eröffnete Wanderausstellung zu Ehren Triolets; das Plakat stammt von Marc Chagall (Lilly Marcou: Elsa Triolet, S. 393).

142 Elsa Triolet: Écoutez-voir, S. 7.

143 Elsa Triolet: La Mise en mots, S. 108.

144 Aragon: Préambule. In: Elsa Triolet: Fraise-des-Bois. Paris: Gallimard 1974, S. XX; zit. bei Lilly Marcou: Elsa Triolet, S. 377f.

145 Elsa Triolet: La Mise en mots, S. 101, 109.

146 «Her last books were an attempt to speak two languages at once - if not Russian and French, then at least French and the language of images» (Elizabeth Klosty Beaujour: Alien Tongues. Bilingual Russian Writers of the ‘First Emigration. Ithaca/London: Cornell University Press 1989, S. 80; zit. nach Unda Hörner: Das Romanwerk Elsa Triolets, S. 129).

147 Huguette Bouchardeau: Elsa Triolet, S. 349.

148 Elsa Triolet: Le rossignol se tait à l'aube. Paris: Gallimard 1970, S. 18ff. et passim. 


\section{Art nouveau und écrivain public: Fragmente einer Theorie der Avantgarde (I)}

Allein: Es sind nicht diese Aspekte, die das Bild der Schriftstellerin Triolet prägen. Was sind die Gründe dafür? Zum einen ist es Triolets poetologischer Selbstkommentar, der diese Komponente ihres Werkes tendenziell camoufliert; zum anderen kultiviert sie einen alternativen Avantgarde-Begriff, der mit den etablierten Kategorien nicht unbedingt allzu gut zu fassen ist.

«Mes mots ne sont ni codés ni truqués [...] J'écris en clair. Je reste dans l'immédiatement déchiffrable, au premier degré», resümiert Triolet ihr Programm einer in mancher Hinsicht trügerischen Simplizität, ${ }^{149}$ die auch den lieu commun nicht scheut, ${ }^{150}$ sondern im Interesse einer intendierten «Kommunikationsästhetik» ${ }^{151}$ rehabilitiert. Diese «fausse transparence» ${ }^{152}$ (Aragon bewundert Triolets Kunst des «mystère en plein jour» ${ }^{153}$ ) hat allerlei Missverständnisse provoziert ${ }^{154}$ - und impliziert auch einen Gestus der Herablassung auf das suggerierte generelle Trivialniveau des Publikums. Bezeichnend ihre Überlegungen zu der von ihr konzipierten Majakovskij-Ausstellung, für die sie wiederum auf intermediale Strategien setzt: «Peut-être un genre bande dessinée, autrement dit «un récit en images> [...] ça peut marcher: Maïakovski simplifié pour les imbéciles et les ignorants. Une sorte d'abécédaire de Maïakovski.» ${ }^{155}$ Plastisch zeigt sich hier der Zwiespalt einer Kunst, die zugleich populär und avantgardistisch sein will und der auch die Aufgabe ästhetischer ‘Volkserziehung〉 zukommt. ${ }^{156}$ "L'art n'est pas un art pour les masses dès sa naissance, il devient un art pour les masses, comme résultat d'une somme d'efforts [...]», beruft Triolet sich auf Majakovskij: ${ }^{157} \ll L a$

149 Elsa Triolet: La Mise en mots, S. 66, 69.

150 In diesem Punkt distanziert Triolet sich selbst von Majakovskij: «Je me servirai des lieux communs, non pas à cause de ma pauvreté en images, mais pour alléger un texte. [...] Je dirais aujourd'hui qu'une certaine banalité dans l'expression ne me déplaît pas. Je continue à penser qu'une prose où chaque mot vaut son pesant d'or est illisible. Le défaut principal des pièces de Maïakovski n'est-il pas dans l'absence de mesures pour rien, si bien que la signification d'un dialogue plein à craquer n'arrive pas entièrement au spectateur, incapable de le suivre dans sa totalité» (Ouverture, S. 20).

151 Unda Hörner: Das Romanwerk Elsa Triolets, S. 10.

152 Alain Trouvé: La Lumière noire d'Elsa Triolet, S. 14.

153 Elsa Triolet: La Mise en mots, S. 65ff. (zit. Aragon S. 69).

154 Alain Trouvé: La Lumière noire d'Elsa Triolet, S. 195.

155 Zit. nach Huguette Bouchardeau: Elsa Triolet, S. 320f.

156 Unda Hörner: Das Romanwerk Elsa Triolets, S. 167.

157 Elsa Triolet: Maïakovski et nous, S. 73. 
compréhension des masses est le résultat de notre lutte, et non la chemise dans laquelle naissent les livres chanceux d'un quelconque génie littéraire» ${ }^{158}$ - leitmotivisch zieht sich dieses Zitat durch ihre literaturpolitischen Statements. ${ }^{159}$

Im Anschluss an Majakovskij, Prototyp jener «écrivains qui possèdent des dispositions particulières qui leur permettent de transmettre l'œuvre», ${ }^{160}$ differenziert sie aber auch ihr Konzept poetischer Transparenz und «obscurité», «pas forcément l'indice de la qualité», aber deshalb auch nicht deren «contre-indication», ${ }^{161}$ vielmehr potentielle Zwischenstufe auf dem Weg zu größerer Klarheit: «[...] lorsque l'hermétisme n'est pas gratuit, il finit par se déchiffrer et devient d'eau de roche.» ${ }^{162}$ Davon zeugt etwa das produktive Rezeptionsschicksal Chlebnikovs, dessen Verse, so Majakovskij, «au début seulement pour sept camarades futuristes» zugänglich gewesen seien, seither aber etliche Dichter und Leser «elektrisiert» hätten ${ }^{163}$ - Leser, die es im Rahmen der hier skizzierten Poetik der Herausforderung ästhetisch wie politisch zu schulen, an das Verständnis avantgardistischer Kunst heranzuführen gilt. Die neue Avantgarde (als Quasi-Synonym gebraucht Triolet den Begriff «art nouveau») adressiert im Sinne dieser Mission im Idealfall erfolgreich die Massen - und sorgt bei den «spécialistes» für Irritation:

\footnotetext{
Et si c'est un symptôme de l'art nouveau que de faire crier la réaction, aujourd'hui l'art véritablement nouveau est celui qui s'exprime en langage clair, par opposition au langage chiffré, et pour lequel souvent il n'existe même pas de code, qui est entièrement truqué.

Et si c'est un symptôme d'art nouveau que de ne pas être compris par tous, l'avant-garde d'aujourd'hui est cet art qui s'exprime en langage clair, mais qui est incompréhensible cette fois-ci non pour la foule, mais pour les spécialistes. Les spécialistes semblent ne pas comprendre qu'on peut appeler pomme une pomme, et créer une œuvre d'art... Créer, parce que l'on ne sait pas tout d'une pomme. ${ }^{164}$
}

Der zeitgenössische Avantgarde-Künstler wird als "une sorte d'écrivain public» charakterisiert, dessen polyvalente Funktion - zwischen dem «magicien d'autrefois» und dem «psychanalyste d'aujourd'hui» - die ganze Problematik des Sprechens/Schreibens für («celui qui exprime pour ceux qui ne savent pas écrire [...] celui qui épouse et devance l'événement, qui l'exprime et le commente, le devine

158 Ebda., S. 74.

159 Vgl. auch Elsa Triolet: Prenez exemple sur nos ennemis [1948]. In: L'Écrivain et le livre, S. $89-117$, hier S. 90.

160 Ebda., S. 109.

161 Elsa Triolet: Maïakovski et nous, S. 72.

162 Elsa Triolet: Ouverture, S. 47.

163 Elsa Triolet: Maïakovski et nous, S. 72.

164 Elsa Triolet: L’Écrivain public [1947]. In: L’Écrivain et le livre, S. 81-87, hier S. 84. 
et l'éclaire socialement et poétiquement parlant» ${ }^{165}$ ), der ambivalenten Rolle des «porte-parole» ${ }^{166}$ mit seinem noch so wohlmeinenden Ventriloquismus ${ }^{167}$ ins Spiel bringt. Die Exempla aus Literatur und abschließend auch Filmkunst, die Triolet anführt, sind sämtlich männlich: «Écrivain public, Éluard [...]; écrivain public, Aragon [...]; écrivain public, le poète soviétique Simonov [...]; écrivain public, Vercors [...]. Écrivains publics, ceux qui se sont fait la voix des camps et des temps muets de l'Occupation...», aber auch: «Écrivains publics, ceux de la Bible, du folklore, les troubadours, Molière, Hugo, Zola, Shakespeare et Dickens, Tolstoï, Barbusse, Gorki, Maïakovski... Écrivains publics, les metteurs en scène de Païsa, de la Bataille du rail, du Tournant décisif...». ${ }^{168}$ Hier findet eine eigenartige Verschiebung statt - von der Avantgarde zum écrivain public, dessen Definition über diese weltliterarische Parade zur Implosion getrieben wird (im Widerspruch auch zu Triolets eigenem Postulat einer historischen Kontextualisierung der Avantgarde).

Eine Konstante in Triolets «Theorie der Avantgarde〉 ist dieser prononcierte Rezeptionsfokus. In der Tat zeichnet die Avantgarde ihre «Rezeptionsorientierung im Sinne eines performativen Appells» aus: Als Ko-Akteur des angestrebten «Rezeptionsbruch[s]» erhält der Leser oder Zuschauer «insofern eine kardinale Funktion, als er zum archimedischen Punkt erklärt wird, der die avantgardistische Welt zu vollenden, eigentlich zuallererst zu erschaffen hätte [...]». ${ }^{169}$

Vom Frühwerk bis zu La Mise en mots, in der Triolet eine Galerie von LeserTypen porträtiert (als Objekt einer besonderen Aversion erscheint der «lecteur spécialisé en littérature» ${ }^{170}$ ), fungiert der «lecteur» als «personnage de plus en plus actant», ja ${ }^{171}$ als «le personnage principal du roman». ${ }^{172}$ «L'auteur vous laisse ce qu'il possédait. Tout, maintenant, dépend de vous. Les personnages du roman vous tirent leur révérence», heißt es am Schluss von Écoutez-voir. ${ }^{173}$ Selbst das 〈Meisterwerk〉 wird nicht in seiner Vollendung autonom gesetzt, sondern ist auf die Immer-wieder-Neuerschaffung durch den Rezipienten angewiesen: «L'œuvre, et même le chef-d'œuvre, n'existe pas pour tous et chacun, il faut être

165 Ebda., S. 85.

166 Vgl. Pierre Bourdieu: Méditations pascaliennes. Paris: Seuil 1997, S. $220 \mathrm{ff}$.

167 Vgl. Gayatri Chakravorty Spivak: The Spivak Reader. Selected Works of Gayatri Chakravorty Spivak. Herausgegeben von Donna Landry/Gerald MacLean. New York/London: Routledge 1996, S. 250.

168 Elsa Triolet: L'Écrivain public, S. 85f.

169 Wolfgang Asholt/Walter Fähnders: 〈Projekt Avantgarde〉, S. $11 f$.

170 Elsa Triolet: La Mise en mots, S. 34.

171 Ebda., S. 65.

172 Ebda., S. 49.

173 Elsa Triolet: Écoutez-voir, S. 345. 
deux pour qu'elle apparaisse: celui qui la crée; celui qui la regarde ou la lit.» ${ }^{174}$ Zugleich beansprucht Triolet über ihren paratextuellen Diskurs - eine zentrale Rolle spielen hier die nachträglichen Vorworte aus den Euvres romanesques croisées - sehr wohl eine gewisse Interpretationshoheit über ihr Werk, das jene intendierte «maîtrise du sens» freilich selbst auf vielfältige Weise unterläuft. ${ }^{175}$

Die Problematik adäquater Rezeption beschäftigt Elsa Triolet nicht nur auf abstrakt-ästhetischer Ebene, sondern auch im Rahmen ihres Engagements beim Comité national des écrivains und beim Comité du livre français. Unter der Devise «Maïakovski prend part à la Bataille du Livre» ${ }^{176}$ wird auch ihr avantgardistischer 〈Schutzpatron» posthum in den Kampf gegen «[l]es deux aspects de la crise du livre, spirituel et commercial» ${ }^{177}$ integriert - doppelte Konter-Offensive gegen die US-Amerikanisierung des Kulturbetriebs und die innerfranzösische Dominanz der politischen Gegnerschaft mit ihren Strategien der Marginalisierung bzw. «Neutralisierung〉 linker Literatur. ${ }^{178}$ Unter dem provokanten Titel «Prenez exemple sur nos ennemis» rechnet Triolet mit ihren Parteigängern (im weiteren Sin$n \mathrm{e}^{179}$ ) ab, selbst schon Opfer und Komplizen der Propaganda-Fiktion des angeblichen «règne de la terreur» im Namen einer konformistischen «esthétique communiste»: «Le malaise qui existe plus spécialement parmi les écrivains de gauche, et de l'extrême gauche, me semble provenir de la difficulté qu'ils ont à synchroniser leurs idées politiques avec leurs idées artistiques.» ${ }^{180}$

\section{Avantgarde und Engagement: Zwischen «idées politiques» und «idées artistiques»}

Die skizzierten Reflexionen rund um die heikle Synchronisation der «idées politiques» und der «idées artistiques» sollen nun an einem Roman expliziert werden, in dem dieses prinzipielle Dilemma der Avantgarde gleich auf mehreren Ebenen durchgespielt wird. Der direkt auf Le Rendez-vous des étrangers folgende Künst-

174 Elsa Triolet: Prenez exemple sur nos ennemis, S. 106.

175 Alain Trouvé: La Lumière noire d'Elsa Triolet, S. 11.

176 Zit. nach Unda Hörner: Das Romanwerk Elsa Triolets, S. 63.

177 Elsa Triolet: Ce que disent de la crise du livre les gens connus et les gens inconnus [Annexes]. In: L'Écrivain et le livre, S. 123-138, hier S. 126.

178 Elsa Triolet: Prenez exemple sur nos ennemis, S. 94.

179 Triolet selbst war trotz ihres langjährigen Engagements und im Gegensatz zu Aragon nie Mitglied des PCF.

180 Elsa Triolet: Prenez exemple sur nos ennemis, S. 104f. 
lerroman Le Monument stellt ein 〈Problemkind` der Triolet-Forschung dar: Konrad Bieber erklärt den 1957 erschienenen Text für «a sad aberration both in taste and in logic»; ${ }^{181}$ Unda Hörner, die Triolets Romanwerk Im Spannungsfeld von Avantgarde und Sozialistischem Realismus untersucht, honoriert ihre avantgardistischen Experimente, befindet ihre Thesenromane mit ihrer konventionellen Form, ihrer «unambiguous, virtually exhortative message» (im Sinne von Susan Rubin Suleimans Definition des roman à thèse ${ }^{182}$ ), ihren theoretischen Exkursen für «streckenweise ungenießbar», wobei sie anmerkt, es sei Triolet «zugutezuhalten, daß sie mit Le monument auch aufzeigt, warum sie sich selbst den Griff zu progressiven künstlerischen Mitteln versagt». ${ }^{183}$ Dieses negative Urteil über Triolets Text als «roman insupportable» ${ }^{184}$ muss man sich nicht unbedingt zu eigen machen, auch wenn Michel Apel-Muller zweifellos in umgekehrter Richtung weit übers Ziel hinausschießt, wenn er Le Monument mit Adolphe und La Princesse de Clèves vergleicht. ${ }^{185}$

Aus der Sicht Triolets selbst ist - wie schon bei Bonsoir, Thérèse - die Gattungszugehörigkeit des Monument nicht so eindeutig: In einem Brief an ihre Schwester vom 6. März 1957 beschreibt sie den Text als «récit, ou nouvelle, ou roman». ${ }^{186}$ Bei allen Defiziten kristallisiert sich jedenfalls eben in Le Monument besonders klar die eingangs umrissene multiple Problemkonstellation rund um Avantgarde und politisches Engagement, Avantgarde und Migration, Avantgarde und Geschlecht, Avantgarde und (Inter-)Medialität heraus. Mit bemerkenswerter Selbstverständlichkeit wird das Drama des politisch engagierten AvantgardeKünstlers ein weiteres Mal an einem männlichen Helden abgehandelt; im Para-

181 Konrad Bieber: Ups and Downs in Elsa Triolet’s Prose. In: Yale French Studies 27 (1961), S. 81-85; zit. nach Unda Hörner: Das Romanwerk Elsa Triolets, S. 114.

182 Susan Rubin Suleiman: Authoritarian Fictions. The Ideological Novel as a Literary Genre. New York u. a.: Columbia University Press 1983, S. 243; zit. nach Unda Hörner: Das Romanwerk Elsa Triolets, S. 12.

183 Ebda., S. $106 \mathrm{ff}$.

184 Vgl. Jean-Pierre Morel: Le Roman insupportable. L'Internationale littéraire et la France. 19201932. Paris: Gallimard 1985.

185 Michel Apel-Muller: C'est à l'histoire de mener la chanson. Préface. In: Elsa Triolet: Le Monument. Paris: Messidor 1990, S. 11-22, hier S. 12; zit. nach Unda Hörner: Das Romanwerk Elsa Triolets, S. 35. Wohl auch in Reaktion auf die vielfach feindselige Rezeption erklärt Aragon Le Monument zu «le chef-d'œuvre d'Elsa Triolet» (Elsa Triolet choisie par Aragon. Paris: Messidor 1990, S. 59; zit. nach Lilly Marcou: Elsa Triolet, S. 328); in gemäßigteren Begriffen würdigt Alain Trouvé (La Lumière noire d'Elsa Triolet, S. 9f.) den Text als Schlüsselwerk, mit dem sich «[1]e passage à une écriture plus réflexive» abzeichnet. Auch Huguette Bouchardeau schätzt diese «sorte de longue nouvelle alerte», die gerade nicht «la même lourdeur que son sujet» besitze (Elsa Triolet, S. 276).

186 Zit. ebda. 
text aktualisiert Triolet die maskulin-militärische Komponente des Begriffs: «Lewka est tombé en première ligne, il appartenait à l'avant-garde de l'art [...]». ${ }^{187}$

In puncto Gender ist dieser heterodiegetisch erzählte, intern auf den Protagonisten Lewka fokalisierte 〈Tauwettertext〉 überaus konservativ; keine Spur von kritischer Distanzierung gegenüber dem Chauvinismus der Hauptfigur («Pour moi, [...] une femme, c'est des mains qui tiennent la maison, et c'est une mère» $\left.{ }^{188}\right)$. Sämtliche relevanten politischen und künstlerischen Auseinandersetzungen finden im homosozialen Mikrokosmos dieses Romans zwischen Männern statt - primär zwischen Lewka und Torsch, «vieux résistant antifasciste» und jetzt Generalsekretär der Kommunistischen Partei seines Landes. ${ }^{189}$ Weibliche Figuren fungieren aus der Sicht des Protagonisten im Wesentlichen als mehr oder minder dekoratives sentimentales Beiwerk; dies gilt für seine in Paris wiedergefundene Jugendliebe, die, nunmehr Gattin eines reichen französischen "gentleman-farmer», ${ }^{190}$ allenfalls noch als Mäzenin brotloser Künstler eine gewisse Rolle spielt und, nostalgische Allegorie, für ihre exilierten Landsleute «un morceau du pays» ${ }^{191}$ inkarniert. Dies gilt aber auch für seine Ehefrau, ehemalige Résistance-Kämpferin mit dem symbolträchtigen Namen «Volia〉, Repräsentantin einer prekären «Freiheit`, ${ }^{192}$ deren Reiz das Kriegsende nicht lange überlebt («Pourquoi s’imaginait-il que Volia n'était plus belle? Mais si, mais si...» ${ }^{193}$ ). Rasch erfolgt die Wiederherstellung der traditionellen Geschlechterordnung, «la camarade belle et courageuse qui s'était battue à côté de lui» verwandelt sich unter den Augen des Protagonisten in einen eifrig kochenden und kindererziehenden häuslichen Engel zurück: «[...] ils avaient un enfant. [...] Sa femme allait

187 Entretien sur l'avant-garde en art et Le Monument d'Elsa Triolet. Extraits. In: Elsa Triolet: Le Monument, S. 217-241, hier S. 223; vgl. auch dies.: L’Écrivain public, S. 87.

188 Elsa Triolet: Le Monument, S. 51.

189 Lilly Marcou: Elsa Triolet, S. 327. Im zeithistorischen Kontext zeugt dieses Porträt von beträchtlicher politischer «audace», wie Marcou (ebda.) betont.

190 Elsa Triolet: Le Monument, S. 40.

191 Ebda., S. 161.

192 Zur semantischen Konstellation der pluralen «Freiheiten` im Russischen, zwischen der mit der französischen liberté korrespondierenden svoboda und der elementaren volja, einem jener 〈unübersetzbaren〉, auto- wie heterostereotyp im Rahmen der Konstruktion einer spezifisch russischen «Mentalität〉 mythifizierten Begriffe, vgl. die entsprechenden Einträge in Barbara Cassin (Hg.): Vocabulaire européen des philosophies. Dictionnaire des intraduisibles. Paris: Seuil 2004: «Liberté» (S. 720-721) und «Svoboda» (Andriy Vasylchenko, S. 1262-1266); sowie Martina Stemberger: Les mots des autres - en d'autres mots. (In-)traductibilité, identité et altérité dans le dialogue franco-russe de l'entre-deux-guerres. In: M. Stemberger/Lioudmila Chvedova (Hg.): Littératures croisées, S. 193-225, hier S. 200ff.

193 Elsa Triolet: Le Monument, S. 77. 
chercher l'eau à la fontaine et faisait la cuisine sur la belle cuisinière de faïence, tout comme l'avait fait la mère de Lewka.» ${ }^{194}$

Explizit reflektiert wird die Problematik Avantgarde und Migration; in diesem Punkt knüpft Le Monument direkt an den Vorgängerroman Le Rendez-vous des étrangers an. «[L]e thème de la création dans une société nouvelle» ${ }^{195}$ wird nicht an der Literatur, sondern an bildender Kunst abgehandelt. Über den polyvalenten Topos der Skulptur wird bei Triolet auch «die Kernfrage des sozialistischrealistischen Romans nach der literarischen Repräsentation des Menschen» aufgeworfen. ${ }^{196}$ Auffallend der konsequente Rekurs auf die Bildhauer-Motivik in ihrem poetologischen Selbstkommentar: «Inutile de chercher des clefs à ce roman, je n'ai jamais rencontré ni Michel ni Elisabeth ni Stanislas ni les autres; j'avais assez de glaise pour les créer de la tête aux pieds», wendet Triolet sich gegen eine Lektüre des Cheval blanc (1943) als Schlüsselroman. ${ }^{197}$ "Quel que soit le mode d'écriture, on se sert du même sable, du même marbre», heißt es 26 Jahre später in La Mise en mots. ${ }^{198}$ In Bezug auf Le Monument honoriert der Maler Boris Taslitzky, der sich bereitwillig mit Lewka als «mon frère», ja Quasi-Doppelgänger identifiziert («Lewka existe. C’est moi. Je veux dire, c'est moi aussi»), Triolets «compréhension magnifique» des künstlerischen Dilemmas, trotz des Fokus auf «un art qui n'est pas le sien». ${ }^{199}$

Aragon erörtert die Frage des Sozialistischen Realismus ebenfalls ausführlich am Beispiel der Malerei und der Bildhauerei. Von Jänner bis Mai 1952 erscheint in den Lettres françaises eine Artikelserie zum Thema, die sich auch als Teil seiner «polémique cachée» (im Sinne Bachtins) mit Breton liest ${ }^{200}$ und eine argumentative Gratwanderung zwischen Verteidigung und Vermittlung der sowjetischen Kunst, Abgrenzung vom ždanovistischen Dogma und einer erneuerten Realismus-Definition darstellt. ${ }^{201}$

Le Monument verdankt seine Genese einem doppelten Impuls aus dem Bereich der bildenden Kunst, angefangen mit der ««affaire du portrait»». ${ }^{202}$ Am 5. März 1953 stirbt Iosif Stalin; anlässlich dieses Ereignisses platzieren Aragon und Pierre

194 Ebda., S. 55.

195 Elsa Triolet: Préface à La Lutte avec l'ange, S. 17.

196 Unda Hörner: Das Romanwerk Elsa Triolets, S. 131ff. («Die Skulptur als Metapher»), zit. S. 133.

197 Zit. nach Huguette Bouchardeau: Elsa Triolet, S. 158.

198 Elsa Triolet: La Mise en mots, S. 133.

199 Entretien sur l'avant-garde en art et Le Monument d'Elsa Triolet, S. $223 \mathrm{ff}$.

200 Maryse Vassevière: Aragon, Breton et la peinture soviétique, S. 113, 249 [Abstract].

201 Ebda., S. 113ff. («Une définition renouvelée du réalisme»), $249 \mathrm{f}$.

202 Elsa Triolet: Préface à La Lutte avec l'ange, S. 12. 
Daix auf dem Cover der Lettres françaises ein Stalin-Porträt Pablo Picassos. Bereits 1947 nimmt Aragon im Gespräch mit Konstantin Simonov eben Picasso und Matisse gegenüber den Attacken der Pravda in Schutz - und zeigt bei dieser Gelegenheit die künstlerischen Grenzen seines ideologischen Konformismus auf:

\begin{abstract}
J'ai défendu l'Union soviétique depuis toujours, et en 1939 j'ai encore défendu l'Union soviétique. En Allemagne également, j'ai défendu l'Union soviétique. C'était dangereux et encore maintenant il y a des gens contre moi à ce propos. Si j'ai défendu l'Union soviétique, c'est parce que je l'aime. Mais je suis communiste, patriote français et je ne peux pas, dans quelque domaine de l'art et de la littérature que ce soit, être une marionnette et un Quisling contre l'art français. N'attendez jamais de moi que je donne l'art français pour les intérêts d'un groupe d'écrivains et peintres soviétiques. ${ }^{203}$
\end{abstract}

Ohne Aragons und Triolets langjährige Unterstützung für den Stalinismus herunterzuspielen - auch zu einer Zeit, da sie schon aus ihrem persönlichen Umfeld zweifellos über die Vorgänge in der Sowjetunion Bescheid wissen, ${ }^{204}$ dabei freilich Stalins Verantwortung noch nicht erkennen (wollen) ${ }^{205}-$, sollte man doch auch nicht übersehen, dass beide - und zwar schon lange vor 1956 und vor allem 1968 - gerade in Kunst- und Literaturfragen immer wieder versuchen, im Rahmen bzw. am Rande der Doktrin gewisse Frei- und Spielräume zu schaffen; diese «stratégie ambiguë»» ${ }^{206}$ ist in Aragons kunstkritischen Texten ebenso zu beobachten wie bei Triolet.

Kurz: Im März 1953 prangt auf der Titelseite der Lettres françaises besagtes Picasso-Porträt des verstorbenen Diktators. Im Gegensatz zu Aragon ist Triolet das Ausmaß dieses Fauxpas sofort klar: «[...] j’ai su aussitôt que nous allions vers un drame. ${ }^{207}$ Die folgenden Tage sind in der Tat dramatisch. Picasso und Aragon werden heftig attackiert, der PCF verlangt eine offizielle Abbitte, die Aragon auch leistet - als Künstler und Intellektueller habe er die Wirkung des Porträts auf den «einfachen Leser〉 falsch eingeschätzt:

203 Beseda s Lui Aragonom i Elzoï Triole [Archives Simonov - Fonds Elsa Triolet-Aragon, CNRS], 2. September 1947; zit. nach Lilly Marcou: Elsa Triolet, S. 292.

204 Im Zuge der «Säuberungen` wird auch Triolets Schwager, General Vitalij Primakov, verhaftet und im Juni 1937 exekutiert.

205 Die Frage, ob Triolet in den dreißiger Jahren über die «crimes du stalinisme» informiert war, beantwortet Marianne Delranc-Gaudric mit: «Très certainement, mais elle n'avait pas conscience de la responsabilité de Staline lui-même» (Elsa Triolet et la vision politique d'Aragon. In: Recherches croisées Aragon/Elsa Triolet 11 [2007], S. 49-58, hier S. 54).

206 Yves Lavoinne: Aragon journaliste communiste. Les années d'apprentissage (1933-1953). Diss., Univ. Strasbourg 1984, S. 692; zit. nach Maryse Vassevière: Aragon, Breton et la peinture soviétique, S. 98.

207 Elsa Triolet: Préface à La Lutte avec l'ange, S. 9. 
Quand ce dessin m'est parvenu, je n'ai pas eu la réaction qui devait être celle du public, voilà le fait. [...] Le grave est justement, qu'habitué de toute ma vie à regarder un dessin de Picasso, par exemple, en fonction de l'œuvre de Picasso, j'aie perdu de vue le lecteur, qui regarderait cela sans se préoccuper du trait, de la technique. C'est là mon erreur. Je l'ai payée très chèrement. Je l'ai reconnue, je la reconnais encore. ${ }^{208}$

Ebendiese Diskrepanz - Schlüsseldilemma der Avantgarde zwischen künstlerischer Innovation und intendierter Massenwirksamkeit - reflektiert Triolet in Le Monument, inspiriert unter anderem von jener «affaire», «un cas exemplaire» der potentiell explosiven «rapports entre la politique et l'art», der angesichts der Enthüllungen des XX. Parteitages nachträglich eine neue Dimension der «ironie macabre» gewinnt. ${ }^{209}$ Im Frühjahr 1953 allerdings befindet Aragon sich in einem Ausnahmezustand; Triolet erinnert daran, wie sie ihn davon abhalten musste, sich mitten im Pariser Verkehr aus dem Auto zu stürzen. ${ }^{210}$

Ein suizidales Ende nimmt die andere Episode, die Triolet als zeitversetzte (Ko-)Inspiration für ihren Roman gedient hat: die Geschichte Otakar Švec', jenes Prager Bildhauers, der in staatlichem Auftrag ein riesiges Stalin-Denkmal erschafft - und noch vor der Einweihung am 1. Mai 1955 Selbstmord begeht, weil er das Werk für ein Desaster hält. ${ }^{211}$ Švec hatte einen interessanten avantgardistischfuturistischen Parcours hinter sich, als er, mit dem Stalin-Projekt zwangsbeglückt, in die Mühlen der Kunstbürokratie geriet. Sein Schicksal wurde mittlerweile auch anderweitig literarisch verarbeitet: Der 1968 nach Wien emigrierte tschechische Autor Rudla Cainer rekonstruiert diese tragischere «Affäres in seinem Roman Stalin aus Granit (2008). ${ }^{212}$ Das für die «Ewigkeit konzipierte, samt Sockel 30 Meter hohe «Monstermonument ${ }^{213}$ wird gerade einmal siebeneinhalb Jahre alt; zur Tauwetterzeit wird aus Moskau signalisiert, dass man es besser loswerden sollte, was aufgrund der Dimensionen und der Platzierung in der Altstadt gar nicht so einfach - und in Triolets Text unmöglich - ist.

Gewiss sollte man in diesem Verwirrspiel von Realität und Fiktion keinen einfachen Kurzschluss herstellen: Zu dem Zeitpunkt, da sie ihren Roman schreibt,

208 Aragon in Les Lettres françaises, 9. April 1953; vgl. Pierre Daix: Aragon. Une vie à changer. Éd. mise à jour. Paris: Flammarion 1994, S. 461; zit. nach Lilly Marcou: Elsa Triolet, S. 312.

209 Elsa Triolet: Préface à La Lutte avec l'ange, S. 12f.

210 Vgl. ebda., S. 12.

211 Vgl. ebda., S. 13.

212 Rudla (Rudolf) Cainer: Žulový Stalin. Osudy pomníku a jeho autora [Stalin aus Granit. Das Schicksal eines Denkmals und seines Schöpfers]. Praha: ARSCI 2008.

213 Vgl. Jitka Mládková: Stalin-Monstermonument. Vor 50 Jahren auf Befehl aus Moskau gesprengt. 21. April 2012. <http://www.radio.cz/de/rubrik/geschichte/stalin-monstermonumentvor-60-jahren-auf-befehl-aus-moskau-gesprengt> [10.02.2018]. 
hat Triolet das Prager Denkmal noch nicht mit eigenen Augen gesehen. ${ }^{214}$ Aber auch ihr Lewka kreiert ein Kollektiv-Monument, das den großen Führer inmitten seiner "grande famille, le prolétariat de partout» zeigt. ${ }^{215}$ Triolet integriert konkrete Anekdoten aus dem damaligen Prag, so den Spitznamen des Denkmals, 〈fronta na maso〉 («Warteschlange beim Fleischhauer〉). ${ }^{216}$ Erst im Sommer 1962, wenige Monate vor der Sprengung, hat sie Gelegenheit, die 〈fronta na maso〉 zumindest aus der Distanz noch zu besichtigen - und gesteht ihre paradoxe Enttäuschung, erscheint ihr das Werk doch weniger monströs als erwartet bzw. erhofft: «Je le regardais longuement: je ne le trouvais pas aussi hideux que l'avaient jugé son créateur et mon héros, Lewka. J'étais déçue à rebours, je l'aurais souhaité plus monstrueux.»" ${ }^{217}$

Triolet verortet ihren Roman in einem eklektischen Phantasiestaat, Konglomerat aus Reiseerinnerungen und künstlerischen Impressionen, in dem sie Elemente der Tschechoslowakei, Polens, Ungarns, Kroatiens, aber auch des ihr persönlich unbekannten Albanien mixt: «Mêlant paysages et styles, l'auteur a situé en Europe Centrale une démocratie populaire qu'il a essayé de rendre vraisemblable, mais qui n'existe sur aucune carte, sauf sur celle de l'imagination.» ${ }^{218}$

«It is not down in any map [...]»: ${ }^{219}$ Mit dieser «programmatische[n] Fiktionalität» distanziert Triolet sich wiederum von einem bloßen «Abbildrealismus». ${ }^{220}$ Der aufmerksamen Leserin entgeht nicht, dass sie im Roman gezielt kleine Verfremdungsmarker setzt, die ihr fiktives Land von der real existierenden Tschechoslowakei differenzieren, ${ }^{221}$ was freilich weder ihre zeitgenössischen Leser noch spätere Interpreten daran hindert, Handlungsort und Helden mit Prag und Švec zu identifizieren. ${ }^{222}$ Aufschlussreich hinsichtlich eines massiven Konflikts zwi-

214 Elsa Triolet: Préface à La Lutte avec l'ange, S. 13.

215 Elsa Triolet: Le Monument, S. 110.

216 Bei Triolet wird daraus der Running Gag eines Autobusfahrers, der jedes Mal, wenn er sich dem Denkmal nähert, seine Durchsage wiederholt: «Dépêchez, dépêchez! Regardez le monde qui m'attend à l'arrêt, là-bas!» - worauf unweigerlich ein Passagier antwortet: «Mais non, ne voyezvous pas qu'ils font la queue devant la boucherie?» (ebda., S. 131).

217 Elsa Triolet: Préface à La Lutte avec l'ange, S. 21.

218 Elsa Triolet: Le Monument, S. 25; vgl. auch dies.: Préface à La Lutte avec l'ange, S. $14 \mathrm{f}$.

219 Herman Melville: Moby-Dick, or The Whale. Ware, Hertfordshire: Wordsworth 1993 [1851], S. 48.

220 Unda Hörner: Das Romanwerk Elsa Triolets, S. 112.

221 So flieht ihr Protagonist zur Zeit des Zweiten Weltkriegs gemeinsam mit «un Tchèque et un Bulgare» (Elsa Triolet: Le Monument, S. 54). «C'est aujourd'hui le match contre les Tchèques, [...] les nôtres ont des chances...», bemerkt der Chauffeur, der Lewka in seine künstlerische Eremitage bringt (ebda., S. 96).

222 Huguette Bouchardeau etwa befindet, «la ville de Prague» sei «reconnaissable à chaque page» (Elsa Triolet, S. 276). «Wenn Le monument allerdings eine überzeitliche Bedeutung haben 
schen auktorialer und lektoraler Intention sind die von Triolet referierten Episoden rund um die Rezeption des Romans in der Tschechoslowakei, wo ihr mangels Übersetzung nur vom Hörensagen bekanntes Werk, wie sie anlässlich ihres Besuches 1962 feststellt, mittlerweile Gegenstand einer regelrechten urbanen Legendenbildung ist. Felsenfest ist das Publikum davon überzeugt, dass Le Monument in Prag und nirgendwo anders spiele, mag die Autorin auch noch so sehr betonen, es gäbe, «mis à part le tragique fait divers d'où j'étais partie, [...] rien de tchèque dans le roman»: «Ce qui pouvait faire croire que j'avais situé Le Monument, paru en 1957, en Tchécoslovaquie, venait d'une ressemblance avec des faits qui se sont produits en 1962, cinq ans après la sortie du roman.» ${ }^{223}$ In mehrfacher Hinsicht holt die Realität die Fiktion in den Jahren nach der Publikation ein: Dies betrifft nicht nur die Sprengung des Denkmals, um die ihr Protagonist vergeblich fleht, sondern auch ihre Schilderung einer gesellschaftlichen Unter- und Gegenwelt in den Katakomben ihrer imaginären Stadt, Anlass für Triolet, ein weiteres Mal «ce mimétisme de la réalité par rapport à la chose écrite» zu reflektieren: «Cette fois, le mimétisme était hallucinant.» ${ }^{224}$

\section{Eine Poetik der «Natürlichkeits? Entwurzelung, Engagement und Einflussangst}

Mit diesen Bemerkungen über die «halluzinatorische` Eigendynamik der Literatur korrespondiert Triolets Kommentar zur Genese ihres Textes: Ausgerechnet dieser Roman über einen Künstler, der sich auf allerlei Um- und Irrwegen seinem Selbstmord entgegenquält, fließt ihr sehr leicht aus der Feder. Le Monument entsteht in wenigen Wochen Ende 1956-Anfang 1957,225 und zwar «avec une rapidité, une facilité, une assurance, comme si tout le roman m'avait été dicté de l'intérieur»,226 ja in einem veritablen Schaffensrausch: «J'écris comme prise d'ivresse. [...] le jour, la nuit, jusqu'à en être ahurie.» ${ }^{227}$

soll, warum läßt sich die unbenannte Volksdemokratie dann so schnell mit der ČSSR identifizieren [...]?», fragt Unda Hörner, und erklärt ihrerseits: «In der Tat spielt Le monument in der ČSSR [...]» (Das Romanwerk Elsa Triolets, S. 112).

223 Elsa Triolet: Préface à La Lutte avec l'ange, S. 20.

224 Ebda., S. $20 \mathrm{ff}$.

225 Vgl. Lilly Marcou: Elsa Triolet, S. 326.

226 Elsa Triolet an Lilja Brik, 6. März 1957; zit. nach Huguette Bouchardeau: Elsa Triolet, S. 276.

227 Zit. ebda., S. 274. 
Konsequent stilisiert Triolet Le Monument zum Produkt einer ganz und gar «naturellement» gedeihenden Kunst. ${ }^{228}$ Dem entspricht die biologische Metaphorik des Paratexts: «Un roman grandit comme un arbre. La graine, le baliveau, des pousses, des branches qui en font d'autres... et voici le livre avec son feuillage, ses ombres, le chant des oiseaux.» ${ }^{229}$ Dies ist ein auf den ersten Blick paradoxes Moment: Diese Autorin, die gegenüber der écriture automatique jene Praxis der 〈Konzentration〉, das «Metier〉 privilegiert, bekennt sich zugleich zu einer Poetik der Organizität, die mit der Motivik der Migration, der Ver- und Entwurzelung interagiert. «Natürlichkeit〉 verlangt Triolet auch von der littérature engagée: «[...] il me semble qu'une œuvre ne peut être engagée que dans la mesure où l'engagement est la chair et le sang de celui qui la crée.» ${ }^{230}$ Auch hier dient ihr als Modell und Maßstab Majakovskij, Prototyp des mit Fleisch und Blut «engagierten〉 Dichters: «Sa poésie ne pouvait être qu'engagée, ou ne pas être [...].» ${ }^{231}$ Unter Rekurs auf ein markantes religiöses Imaginarium («ne sera valable que l'œuvre de celui pour qui le vin et l'hostie seront devenus chair et sang» ${ }^{232}$ ) wird jegliche ideologische Auftragsarbeit verworfen, wobei Triolet in doppelter ästhetischer und politischer Intention zwischen künstlerischer «Natürlichkeit〉 und «Freiheit» unterscheidet:

Celui qui suit son inspiration écrit naturellement. Je dis bien: naturellement, et non: librement. Car on peut choisir librement de ne pas écrire comme cela vous serait naturel. Pour de bonnes et de mauvaises raisons. Parce qu'on veut suivre ses convictions théoriques, ou qu'on fait un calcul artistique, politique. Et l'on fera de «l'art intérieur», quand naturellement on aurait dû faire une œuvre réaliste, ou on fera de l'art de propagande quand on a

228 Elsa Triolet: Préface à La Lutte avec l'ange, S. 17.

229 Ebda., S. 19. Dieses poeto-ornithologische Motiv stellt eine weitere Konstante in Triolets künstlerischer (Selbst-)Reflexion dar. «[...] aussi naturellement que se cherchent et se trouvent les individus d'une même espèce animale - chiens, chats, oiseaux - je n'avais pour amis que des poètes: peintres, philologues, historiens ou poètes, tous mes amis faisaient des vers», heißt es in ihrer «Ouverture» zu den Euvres romanesques croisées (S. 14). Verfolgt von jenem «espritperroquet, oiseau insaisissable», den er nicht abzuschütteln vermochte, wird der Protagonist des Monument zum suizidalen 〈Vogelmenschen`: «L'homme-oiseau que les ailes refusent de tenir dans l'air, se tue...» (S. 194f.). In La Mise en mots erinnert Triolet sich an jene «inoubliable émission» (S. 139) aus dem Jahr 1968 («Vivre et parler»), da Roman Jakobson - in Gesellschaft François Jacobs, Claude Lévi-Strauss' und Philippe L’Héritiers - die «Sprache` der Vögel kommentierte (vgl. Marianne Delranc-Gaudric: Elsa Triolet, Maïakovski, Lili et Ossip Brik, Jakobson, Aragon..., S. 85f.).

230 Elsa Triolet: Maïakovski et nous, S. 59.

231 Und wiederum: «L'engagement était sa chair et son sang» - diese Formel zieht sich durch Triolets Überlegungen zum literarisch-künstlerischen «Engagement», im reflexiven wie im transitiven Sinn (ebda.).

232 Ebda., S. 61. 
envie de parler des petits oiseaux. [...] Les vrais surréalistes ont fait des œuvres qui étaient belles, leurs imitateurs n'ont fait que de la camelote. Qui sait si, parmi ces derniers, il n'y a pas d'écrivains qui auraient fait naturellement des œuvres réalistes valables? N'est pas surréaliste, ni réaliste, qui veut.... 233

Derart konstituiert der in sich signifikant brüchige poetologische Diskurs Triolets ein bemerkenswertes Spannungsfeld zwischen avantgardistischem Anspruch und Organizitätsideal. «Il faut à l'écrivain du génie ou un tempérament exceptionnel pour rester naturel. Parce que tous les écrivains se laissent influencer [...]. Il faut beaucoup de courage pour continuer à écrire naturellement [...]», konstatiert sie, deren Texte über die Jahrzehnte von einer ausgeprägten Ambivalenz zwischen Einflussangst und Einflusslust zeugen:

Je suis heureuse qu'au ciel on voie varier les tons les plus tendres, que les roses aient le parfum de rose, que brillent des étoiles d'argent, que les rossignols chantent sans s'occuper d'être si démodés. Les rossignols, ils s'en balancent des innovations, des trucs. Ne pourrais-je pas, moi aussi, me débarrasser de la crainte pourrie? ${ }^{234}$

In Écoutez-voir artikuliert Protagonist «Austin〉, der sich von seinen künstlerischen Aktivitäten schließlich frustriert abwendet, als Nachtclub-Betreiber zu Reichtum und - vor dem Hintergrund der entsprechenden avantgardistischen Obsessionen nicht ganz unschuldig - als Autorennfahrer zu Tode kommt, die Frustration des kreativen Menschen in einer längst sausgeschaffenen` Welt:

Les Âmes mortes [...] sont déjà écrites. Et Faust aussi. Et déjà Le Soulier de satin est un titre. [...] Tout ce que j'aurais aimé écrire est déjà écrit. Tous les beaux tableaux sont déjà peints. La gamme n'a que huit notes. Un voleur de metteur en scène a déjà tourné un film pour dire qu'il n'avait rien à dire. C'est moi qu'il a volé, le fainéant. ${ }^{235}$

Die «große Literatur der anderen fungiert aber auch als Motor und Inspiration des eigenen Schreibens: «Pour me remettre au travail, il m'est indispensable de relire Dostoïevski. Il va me bouleverser d'admiration, je me jetterai sur ma plume. Cela m’a déjà aidée deux fois.» ${ }^{236}$

In Le Monument ist diese Problematik vom ersten Absatz an präsent. Die Syntax selbst spiegelt die zugleich faszinierende und erdrückende Gegenwart der Vergangenheit und ihrer Kunst in einer Palimpsest-Stadt, «entièrement habitée par un peuple de statues», die den Protagonisten auf Schritt und Tritt begleiten; ${ }^{237}$

233 Elsa Triolet: Prenez exemple sur nos ennemis, S. 112f.

234 Elsa Triolet: Ouverture, S. 20.

235 Elsa Triolet: Écoutez-voir, S. 93.

236 Zit. nach Huguette Bouchardeau: Elsa Triolet, S. 83.

237 Elsa Triolet: Le Monument, S. 30. 
ihrerseits inkarniertes Stück Kunstgeschichte, erscheinen der kindliche Lewka und seine Freundin Leïla als Teil dieser großen Familie aus Stein. ${ }^{238}$ Dieser Tausch der Attribute, das im Freud'schen Sinne Unheimliche dieser Grenzüberschreitung zieht sich durch die Texte Triolets, L'Âme wie Écoutez-voir, wo jenes Leitmotiv des «peuple de statues», ${ }^{239}$ einer geheimnisvoll belebten «foule peinte» samt metaleptischer «confusion» wiederkehrt. ${ }^{240}$

Als «jeune prodige» wird Lewka, der immer noch den statuesken «saints de son pays» ähnelt und mit dem «caractère national» seines Talents für Furore sorgt, im Jahr 1933 nach Paris geschickt. ${ }^{241}$ Dort durchlebt er eine kubistische Phase, begeistert sich für «[l]es dernières œuvres de Brancusi, de Zadkine, de Lipchitz». ${ }^{242}$ Als man ihm aufgrund seiner Opposition gegen das korrupte monarchische Regime seiner Heimat sein bescheidenes Stipendium streicht, verlegt er sich auf folkloristische Keramik-Produktion. ${ }^{243}$ Die Leserin erinnert sich unweigerlich an Triolets Erfolge als Schmuck-Designerin (u.a. für Elsa Schiaparelli), die dem Paar in schwierigen Zeiten den Lebensunterhalt sichern. In der Schilderung der Pariser Existenz Lewkas finden sich trotz Geliebten und Parties Triolets Grundmotive der Einsamkeit und Entfremdung wieder. Angesichts der Nachricht vom Tod seiner Eltern sieht sich ihr Protagonist auf sein Außenseitertum zurückgeworfen - ferner und gleichgültiger scheint ihm die lebendige Menge in Paris als das Statuenvolk seiner Heimatstadt: «Qu'était pour lui la foule de gens qu'il connaissait à Paris? du provisoire, des amis à la gomme, sans racines dans sa vie, des étrangers qui riaient quand Lewka parlait leur langue et qui ne connaissaient pas la sienne.» ${ }^{244}$

Seine «Entwurzelung〉 ist auch kreativer Natur. Mit seinen kubistischen Experimenten weicht Lewka bereits - rebellischer «geste de désespoir» - von seiner «natürlichen` Affinität zum Figurativen ab. Bald holt die Nostalgie der verlorenen Unschuld den jungen Künstler ein, der seine «façon de voir» verloren hat:

238 Ebda., S. 32.

239 Elsa Triolet: Écoutez-voir, S. 139. Auch die jugendlichen Straßenkünstler in Paris, «[u]ne caste à part», werden als «[u]n peuple de statues vulnérables et fragiles» metaphorisiert (ebda., S. 92).

240 «La foule peinte des tableaux, saints, martyrs, rois, ducs, moines et héros continuait la foule sans auréoles des rues. Je me laissais glisser avec complaisance dans la confusion entre les deux et [...] c'est sans étonnement que j'aperçus une femme descendue d'une des toiles que j'avais vues dans un palais: [...]» (ebda., S. 29f.).

241 Elsa Triolet: Le Monument, S. 33, 36.

242 Ebda., S. 41.

243 Ebda., S. 42ff.

244 Ebda., S. 45. 
Avant de venir à Paris, je regardais le monde, je le voyais à ma façon, et cette façon, je pouvais l'exprimer, presque... C'était dans mes moyens. Et maintenant j'ai perdu ma façon de voir, et, ce que je vois, je le vois à la façon de l'un ou de l'autre... Écoute, je te regarde, et je te vois en dessin de modes, [...] ... ou, si tu veux, en Picasso, [...] ... Mais ce n'est pas dans mes moyens, ni de faire un dessin de modes, ni un Picasso, et je ne peux plus faire comme moi-même.... ${ }^{245}$

Fürs Erste erlösen ihn der Kriegsausbruch und die Internierung als «verdächtiger〉 Ausländer in einem südfranzösischen Lager: «Au camp, Lewka n'était plus obligé de s'occuper de l'art et cela lui fut d'un grand soulagement.» ${ }^{246}$

\section{Auf der Suche nach der «ligne juste»: Fragmente einer Theorie der Avantgarde (II)}

In seiner nunmehr sozialistischen Nachkriegs-Heimat sucht der Protagonist nach einer «Leerstelle` in einer Stadt, in der für neue Kunst nirgends mehr Platz zu sein scheint. Sein Traum von einem Stalin-Denkmal in einem der modernen Stadtviertel, «dans le voisinage des pylônes, de l'immense antenne de radio, des édifices blancs, quadrillés et rayés de vitres luisantes, du stade pour cent mille personnes, du barrage qui allait électrifier tout le pays», scheitert am Wunsch der Autoritäten, die darauf bestehen, das Monument prominent «à la pointe de la vieille ville» unterzubringen, «avec laquelle il n'avait rien à faire... On le verrait de partout. De partout!». ${ }^{247}$

Hier manifestiert sich die prinzipielle Problematik eines nach wie vor einer obsoleten 〈Fortschritts〉-Idee verpflichteten Kunstbegriffs; in diesem Sinne ist Triolets Antiheld als Pionier nicht nur der Avantgarde, sondern auch von deren Selbst-Elimination zu lesen, sein Suizid als physische Realisierung jenes «theorydeath of the avant-garde», Paul Mann zufolge «ihre subversivste Phase» samt Implosion jedes «Innovationsmodell[s]». ${ }^{248}$

Wiederholt flüchtet Lewka auf der Suche nach der ästhetischen und ideologischen «ligne juste» ${ }^{249}$ ausgerechnet ins Museum, das so seine ganze Ambivalenz als heterotope Gegenwelt entfaltet. Leidenschaftlich proklamiert er das avantgar-

245 Ebda., S. $49 \mathrm{ff}$.

246 Ebda., S. 53.

247 Ebda., S. 111f.

248 Paul Mann: The Theory-Death of the Avant-Garde. Bloomington/Indianapolis: Indiana University Press 1991, S. 74; zit. und kommentiert bei Wolfgang Asholt/Walter Fähnders: 〈Projekt Avantgardes, S. $12 \mathrm{f}$.

249 Elsa Triolet: Le Monument, S. 167. 
distische Ideal einer Fusion von neuer Kunst und neuer Lebenspraxis - und übersieht dabei seine eigenen Reaktionen als professioneller Rezipient, der doch wieder bevorzugt vor den "paysages du Canaletto national» ${ }^{250}$ seinen Gedanken nachhängt, die museale Sphäre prekär autonomer Kunst als Oase relativer Freiheit erlebt, nicht nur Evasions-, sondern vor allem auch Reflexionsort, von dem aus die Welt «draußen ` hinterfragt werden kann. ${ }^{251}$

Wie Triolet selbst begreift ihr Protagonist Kunst als Dialog: «[...] il aurait dû se faire peintre et non sculpteur, la peinture permettait de dire bien plus de choses à ses interlocuteurs!» ${ }^{252}$ Als Positivbeispiel für einen gelungenen Sozrealismus schildert Triolet aus Lewkas Perspektive einen Landschaftsmaler, «bête noire» der Kollegenschaft. ${ }^{253}$ Aufschlussreich auch hier die Querverbindung zu Aragon, der in seiner Artikelserie zur sowjetischen Kunst - im Kontrast zur Mediokrität diverser anderer Stalin-Preisträger ${ }^{254}$ - speziell die landschaftsmalerischen «poèmes-picturaux» Georgij Nisskijs würdigt. Dessen Euvre, «foyer d'une intense réflexion esthétique», symbolisiert für Aragon die Überwindung eines «réalisme socialiste étroit»; ${ }^{255}$ deutlich dagegen die relative Antipathie gegen die «sculpture monumentale» eines Matvej Manizer. ${ }^{256}$

Angesichts all jener ins Leere sprechenden Gemälde beschließt Triolets Protagonist, wie Nisskij aufgrund seiner formalistischen Vergangenheit suspekt, ${ }^{257}$ mit der Masse kommunizierende Kunst mitten in der gesellschaftlichen Realität zu schaffen: «Son monument à lui avait des interlocuteurs.» ${ }^{258}$ Doch auch er scheitert an jenem doppelten Dilemma zwischen Popularität und Avantgarde, Tradition und Innovation.

$\mathrm{Zu}$ Beginn seiner Arbeit besteht er darauf, sein Atelier - ein umfunktioniertes Kirchenschiff - von aller alten Sakralkunst leerräumen zu lassen: «Cela lui donnerait un complexe d'infériorité et une irrésistible envie d'imiter.» ${ }^{259}$ Die vermeint-

250 Ebda., S. 165.

251 Vgl. Peter Bürger: Theorie der Avantgarde, S. 73; Wolfgang Asholt/Walter Fähnders: «Projekt Avantgardes, S. 5.

252 Elsa Triolet: Le Monument, S. 166.

253 Ebda., S. 168.

254 Vgl. Nr. 12 seiner Artikelserie (Parenthèse sur les prix Staline. In: Les Lettres françaises 409); zit. nach Maryse Vassevière: Aragon, Breton et la peinture soviétique, S. 95.

255 Ebda., S. 111f.

256 Vgl. Nr. 2 (Il y a des sculpteurs à Moscou. In: Les Lettres françaises 399) und Nr. 3 (Un sculpteur soviétique vous parle. In: Les Lettres françaises 400); zit. nach Maryse Vassevière: Aragon, Breton et la peinture soviétique, S. 95, 100.

257 Vgl. ebda., S. 102.

258 Elsa Triolet: Le Monument, S. 166.

259 Ebda., S. 112. 
liche Tabula rasa füllt sich freilich auf der Stelle neu. Unschwer erkennt ein Kollege - der, seinerseits im Konflikt mit seiner «natürlichen`Berufung, nach außen hin pflichtgetreu dem Sozialistischen Realismus huldigt und privat seine skandalöse Liebe zur impressionistischen Malerei kultiviert - in Lewkas Modell die Spuren des aus der Kirche verbannten Retabels wieder: «Dis donc, Lewka, tu as beaucoup regardé le retable de l'église Sainte-Barbe... Il t’a collé aux doigts!...» ${ }^{260}$ Mit scharfem Blick erfasst auch der Kunstminister, bald darauf Opfer der nächsten Repressionswelle, die Brüche und Widersprüche eines Werkes, das zwischen Vergangenheit und Zukunft, Pariser Avantgarde und Kirchenkunst, «art populaire» und «art monumental» in der Schwebe bleibt: «Vous devriez, camarade Lewka, vous décider pour une chose ou une autre: [...] votre œuvre est hybride.» ${ }^{261}$

〈Hybrid〉 ist dieses Werk auch in anderer Hinsicht. Le Monument illustriert die diffizile Situation einer Avantgarde, die sich nicht mehr in Opposition zum Regime befindet, ihre gesellschaftlichen Ambitionen jedoch rasch genug degenerieren sieht. Als Dissident im Pariser Exil ist der Protagonist zwar in materieller Not, aber in einer ideologisch erfreulich eindeutigen Lage; während des Zweiten Weltkriegs wird er - weniger politisch denkender denn intuitiver - Kommunist («cela allait dans le sens de ses propres pensées. Ou, plutôt, de ses sentiments $[\ldots] »^{262}$ ), kämpft in der Widerstandsbewegung seines Heimatlandes, erlebt die «exaltation» der Befreiung vor Ort mit. ${ }^{263}$ Enthusiastisch beobachtet er, «comme le socialisme naissant donnait de l'intérêt à la vie de chacun, [...] comme il insufflait la passion!». ${ }^{264}$ Doch nicht auf Dauer halten sich die revolutionäre Begeisterung, der Glaube an die Sinnhaftigkeit des eigenen Daseins. Auch auf Basis ihrer persönlichen Erfahrung reflektiert Triolet die Résistance und unmittelbare Nachkriegszeit als «Modellsituation», ${ }^{265}$ punktuell erfolgreiche Überwindung jener «Wirkungslosigkeit der Kunst in der bürgerlichen Gesellschaft», gegen die die Avantgarde rebelliert. ${ }^{266}$ Nicht umsonst sind diese Jahre für Triolet wie für Aragon - trotz schwieriger und teils gefährlicher Lebensumstände - höchst produktiv: Hier wachsen ihrer literarischen Tätigkeit der soziale Nutzen, ${ }^{267}$ «die

260 Ebda., S. 114f.

261 Ebda., S. 118.

262 Ebda., S. 53.

263 Ebda., S. 54.

264 Ebda., S. 57.

265 Unda Hörner: Das Romanwerk Elsa Triolets, S. 103.

266 Peter Bürger: Der französische Surrealismus. Studien zur avantgardistischen Literatur. Um neue Studien erweiterte Ausgabe. Frankfurt a.M.: Suhrkamp 1996, S. 59; zit. nach Gisela Febel: «Poesie-Erreger» oder von der signifikanten Abwesenheit der Frau, S. 81.

267 Aragons und Triolets «works had a wide appeal and played a significant part in keeping up the morale of the common people [...]. Many who had seldom bothered to open a book before the 
politische Bedeutung [...] fast automatisch» $\mathrm{zu},{ }^{268}$ fallen individuelle «conception de l'art» und kollektive "cause du peuple» temporär zusammen. ${ }^{269}$ In diesem Sinne theoretisiert Triolet die Literatur der Résistance später ausdrücklich als mittlerweile historische Avantgarde; nicht auf formaler Basis, sondern hinsichtlich ihrer "gesellschaftlichen Effizienz» konstruiert sie eine «Verwandtschaftsbeziehung» zwischen Majakovskij und Aragon. ${ }^{270}$ Die Desillusion folgt auf dem Fuß: «[...] Au fur et à mesure que la Libération perdait ses belles couleurs, ma littérature et moi-même semblions perdre nos qualités», erinnert sich Triolet. ${ }^{271}$

Einen ähnlichen Parcours - mit letalem Ende - schreibt sie ihrem Protagonisten zu. Lewka fungiert aber auch als Sprachrohr eines noch unkritischen Stalinismus; in seinen Augen erscheint Stalin als «[u]n personnage de légende. Un homme qui savait et pouvait tout» ${ }^{272}$ und dem, wie der Sowjetunion insgesamt, «une reconnaissance fraternelle et éternelle» gebührt. ${ }^{273}$ Triolet akzentuiert die Bewusstseins- und Wissensdiskrepanz zwischen ihrer Figur, die im Jahr 1953 zum Revolver greift, und einer narrativen Instanz, die die weitere politische Entwicklung bereits kennt:

[...] tout imaginaires qu'ils fussent, ce sculpteur et son pays, et bien que mon récit se passât avant 1956, il allait baigner dans le bain révélateur du XXe Congrès. Moi, l'auteur, j'avais le privilège des adultes face aux enfants, de l'oracle, du prophète face aux simples mortels; je savais ce que mon héros ne savait pas, j'écrivais en conséquence, en connaissance de cause. $^{274}$

Im Paratext gibt sie zwar eine primär poetologische Lesart vor: «Le problème central du livre est un problème d'ordre esthétique [...] J'ai voulu placer le problème dans un pays où l'art, déjà libéré du commerce, subit d'autres impératifs...»». ${ }^{275}$ Die

war, now found themselves eagerly awaiting the messages of hope and confidence that Resistance literature provided», betont Max Adereth (French Resistance Literature. The Example of Elsa Triolet and Louis Aragon. In: David Bevan [Hg.]: Literature and War. Amsterdam/Atlanta: Rodopi 1990, S. 123-134, hier S. 124; zit. nach Leslee Poulton: The Influence of French Language and Culture, S. 181).

268 Unda Hörner: Das Romanwerk Elsa Triolets, S. 58.

269 Elsa Triolet: Le Monument, S. 76.

270 Unda Hörner: Das Romanwerk Elsa Triolets, S. 59.

271 Elsa Triolet: Préface à la clandestinité. In: Euvres romanesques croisées d'Elsa Triolet et Aragon. Bd. 5: Le premier accroc coûte deux cents francs (1). Paris: Laffont 1965, S. 27; zit. nach Lilly Marcou: Elsa Triolet, S. 277.

272 Elsa Triolet: Le Monument, S. 108.

273 Ebda., S. 82.

274 Elsa Triolet: Préface à La Lutte avec l'ange, S. 15.

275 Ebda., S. 19f. 
kontroverse Rezeption des Romans, der, so Triolet, für «plus de remous que tous les autres» ${ }^{276}$ gesorgt habe, dominieren besagte «autres impératifs». Im zeitpolitischen Kontext provoziert der Text eine geradezu «explosive» Reaktion, ${ }^{277}$ auch und vor allem «parmi les communistes de tous les pays qui souffrent quand on parle de la corde du pendu». ${ }^{278}$ Lange bevor Triolet und Aragon sich durch ihre Kritik an der sowjetischen Reaktion auf den Prager Frühling definitiv unbeliebt machen (Triolet prangert in drastischen Worten die «nazis de Moscou» $\mathrm{an}^{279}$ ), missfällt Le Monument: Jahrelang wird der Roman in keinem einzigen Warschauer-Pakt-Staat (außer Ungarn) übersetzt. ${ }^{280}$ Für Marcou wird Triolet mit diesem kathartischen «conte philosophique» zur «non-conformiste»; ${ }^{281}$ für Bouchardeau ist Le Monument «le premier roman français anti-stalinien». ${ }^{282}$ Zweifellos enthält der Text seine Dosis «Kommunismuskritik» ${ }^{283}$ - doch von Interesse ist er vor allem als innerlich widersprüchliches Übergangswerk; Triolet verwahrt sich gegen eine Lektüre als «une attaque du seul stalinisme». ${ }^{284}$

Ihr Protagonist - von der kommunistischen Regierung seines Landes als Paradekünstler instrumentalisiert, der nach allerlei kubistisch-abstrakten Verirrungen zum Sozrealismus findet - wird als Repräsentant einer «génération sacrifiée» ${ }^{285}$ zusehends zur Märtyrerfigur. Frappierend wiederum die religiöse Motivik im Roman wie im Paratext: «Que d'artistes d'avant-garde ont été crucifiés par les conditions morales et matérielles qui leur ont été faites!» ${ }^{286}$ In Bezug auf die Geschichte eines anderen suizidalen Künstlers, Frank Mosso aus Le Rendezvous des étrangers, spricht Triolet von einer «Machine infernale», «une machine à la Kafka». ${ }^{287}$ Hier ist die Schuldzuschreibung klar: Der US-amerikanische Maler im Exil ist ein Opfer der McCarthy-Ära. ${ }^{288}$ Für Lewka, Sohn eines Uhrmachers (poetologisch-philosophisch nicht ganz unschuldige Profession), wird das Stalin-

276 Ebda., S. 16.

277 Lilly Marcou: Elsa Triolet, S. 327.

278 Elsa Triolet: La Mise en mots, S. 97.

279 Zit. nach Lilly Marcou: Elsa Triolet, S. 368.

280 Elsa Triolet: Préface à La Lutte avec l'ange, S. 16.

281 Lilly Marcou: Elsa Triolet, S. 326.

282 Huguette Bouchardeau: Elsa Triolet, S. 260.

283 Unda Hörner: Das Romanwerk Elsa Triolets, S. 110.

284 Huguette Bouchardeau: Elsa Triolet, S. 278.

285 Elsa Triolet: Le Monument, S. 75.

286 Entretien sur l'avant-garde en art et Le Monument d'Elsa Triolet, S. 221.

287 Elsa Triolet: Préface à La Lutte avec l'ange, S. 18.

288 In Umkehrung der Situation in Le Monument ist hier figurative Kunst per se ideologisch verdächtig, während «l'art abstrait» als «un excellent témoignage d'anticommunisme» fungiert (Elsa Triolet: Le Rendez-vous des étrangers, S. 188). 
Monument zur «Schicksalsmaschine»; quer durch den Roman und die anschließende Diskussion zieht sich die Frage, ob er versagen «musste` oder nicht.

«Je me suis tué, parce que je n'ai pas été à la hauteur de mon devoir d'artiste communiste. $\mathrm{Ou}$ alors... Je meurs pour des raisons esthétiques, morales et politiques...», skizziert der Protagonist - nicht ohne Pathos - seinen Abschiedsbrief. ${ }^{289}$ Sein Scheitern ist relativ, im Prozess einer fundamentalen ästhetischen wie ideologischen Neuorientierung stellt das missglückte Monument eine nötige «étape», ja sogar «une étape valable» dar. ${ }^{290}$ Noch während der Arbeit wird Lewka bewusst, dass er sich auf einem potentiell fruchtbaren Irrweg befindet; schockiert hört er mit an, wie ein Gehilfe sein Denkmal mit «la Bavaria de Munich» vergleicht. ${ }^{291}$ Allein: Als Rädchen in einer ganzen Propagandamaschinerie, «pris dans un engrenage qui ne lui permettait plus aucun mouvement», ${ }^{292}$ kann er das Projekt nicht mehr stoppen.

Rat- und hilflos betrachtet er seine hybride Kreation, «une sorte d'immense blockhaus de ciment», 293 "[é]norme et monstrueux comme une bête antédiluvienne sur ses pattes de derrière!». ${ }^{294}$ Zum «désastre» ${ }^{295}$ wird sein Experiment aufgrund des externen Zwanges zur Vollendung: Insofern reflektiert Le Monument auch die Problematik des Werkes, eines hier tonnenschwer materiell präsenten Werkes, das sich zur Verzweiflung des Künstlers nicht mehr aus der Welt und aus dem Panorama seiner Heimatstadt schaffen lässt. Und auch wenn Triolet ihrem Protagonisten ein explizites Mea culpa in den Mund legt («[...] j’ai fait ce monument hideux. Il est hideux, j'en conviens, et c'est là mon crime. Je précise: mon crime ${ }^{296}$ ), wird doch klar, dass der Roman die 〈unmögliche〉 Position einer nicht nur politisch engagierten, sondern auch politisch kommandierten Avantgarde adressiert. $^{297}$

289 Elsa Triolet: Le Monument, S. 198.

290 Ebda., S. 160.

291 Ebda., S. 123.

292 Ebda., S. 129.

293 Ebda., S. 146.

294 Ebda., S. 134.

295 Ebda.

296 Ebda., S. 172.

297 «On ne peut évidemment pas les [les gens de lettres] commander [...]», unterstreicht Triolet (Maïakovski et nous, S. 61); auch an anderer Stelle wird die Idee jeglichen 〈Kommandos〉 politischer wie psychologischer Natur - in Bezug auf die künstlerische Arbeit zurückgewiesen: «[...] c'est ce qu'on appelle communément l'inspiration. [...] C'est variable comme les hommes, et ça ne se commande pas» (Prenez exemple sur nos ennemis, S. 110). 


\section{Politik, Poetik, Perspektive: Sozrealismus als Avantgarde?}

Im Anschluss an die Publikation entspinnt sich eine Diskussion, in deren Rahmen Triolet ihren Avantgarde-Begriff präzisiert. ${ }^{298}$ Le Monument (samt Paratext) zielt auf eine durchaus kritische Verteidigung und Reinterpretation des Sozialistischen Realismus ab, via Einschreibung in die Tradition der Avantgarde; strategisch wird «la plus grande partie de l'œuvre de Maïakovski» dem Sozrealismus inkorporiert $^{299}$ und auch die politisch sanktionierte Résistance-Literatur ins Spiel gebracht. In der Debatte um «l'avant-garde et Le Monument d'Elsa Triolet» wird dieser Kurzschluss zwischen Avantgarde und Sozialistischem Realismus bereitwillig nachvollzogen, Triolet selbst von Vladimir Pozner zum «romancier d'avantgarde», ihr Roman zum Exempel jener Synthese erklärt. ${ }^{300}$ Le Monument sei, so auch Pierre Daix, «un livre d'avant-garde», und zwar «par son sujet certes, mais aussi par la manière dont Elsa Triolet a su créer les moyens d'expression romanesque nécessaires à la conduite d'un tel sujet». ${ }^{301}$

Der Rekurs auf das Erbe der Avantgarde dient aber auch zur Relativierung der Doktrin. «Une œuvre, cela vaut toutes les théories...», proklamiert Lewka; ein Statement, das ein regimetreuer Kollege als «monstrueux» verwirft, ${ }^{302}$ das Triolet aber in eigenem Namen aufgreift: «Une théorie, et puis l'œuvre? Une œuvre, et puis la théorie? En définitif, c'est toujours l'œuvre qui gagne.» ${ }^{303}$ Wenn sie betont, «le chemin de la création» sei nicht «toujours le même que celui de l'intelligence politique», ${ }^{304}$ so mag das aus heutiger Perspektive trivial erscheinen; im damaligen Kontext ist dies eine geradezu <ikonoklastische> Position. ${ }^{305}$

298 Am 29. März 1958 organisiert die Union des étudiants communistes im Rahmen ihrer Journées nationales eine öffentliche Debatte; die Beiträge werden im Mai in La Nouvelle Critique publiziert (Entretien sur l'avant-garde en art et Le Monument d'Elsa Triolet, S. 217ff.).

299 Ebda., S. 222. Strategisch wird der Sozrealismus einerseits so weit gefasst, dass er nicht nur Majakovskij, sondern virtuell einen nicht unbeträchtlichen Teil der Weltliteraturgeschichte umfasst; auf der anderen Seite werden eventuelle Misserfolge argumentativ ausgelagert: 〈Schlechte〉 Kunst mit dem Anspruch, Sozrealismus zu sein, ist einfach gar keiner (vgl. ebda., S. 238f.).

300 Ebda., S. 235.

301 Ebda., S. 240f.

302 Elsa Triolet: Le Monument, S. 86.

303 Elsa Triolet: Ouverture, S. 46.

304 Elsa Triolet: Maïakovski et nous, S. 61.

305 Vgl. Marie-Thérèse Eychart: Préface. Elsa Triolet dans la bataille idéologique et littéraire de l'après-guerre. In: Elsa Triolet: L'Écrivain et le livre, S. 5-21, hier S. $14 \mathrm{f}$. 
Wenig später wird in Le Monument freilich der gleichen Figur eine Apologie des Sozrealismus in den Mund gelegt: «La théorie est bonne, c'est l'artiste qui est mauvais: moi!» ${ }^{306}$ Triolet verfolgt eine argumentative Doppelstrategie, die das Primat des Kunstwerks gegenüber jeglicher Ideologie reklamiert und parallel den Sozialistischen Realismus als paradoxe Garantie kreativer Freiheit zu rehabilitieren versucht. Letztere wird politisch rückgekoppelt, ist innovative Kunst doch notwendig «à gauche»: «[...] en règle générale, quand l'homme cesse d'être de gauche, son œuvre le suit et devient réactionnaire.» Dies illustriert das Paradebeispiel «Marinetti, le père du futurisme devenu fasciste»: «[...] l'art du futuriste Marinetti n'avançait plus d'un pas. Comme aujourd'hui celui du surréaliste Breton.» ${ }^{307}$

Eine Historisierung der Avantgarden der Zwischenkriegszeit - samt Abrechnung mit einem verspäteten Pseudo-Surrealismus - unternimmt Triolet schon in ihrem Vortrag «Maïakovski et nous» aus dem Jahr 1947. Hier analysiert sie die Mechanismen ideologischer und kommerzieller Rekuperation, die Instrumentalisierung einer ins Hintertreffen geratenen Avantgarde als Alibi:

Il est normal que le Figaro publie aujourd'hui André Breton, chose impensable en 19251930, quand le surréalisme était à l'avant-garde de l'art. C'est normal que la réaction admire ce qui ne peut plus lui faire du mal [...]. Il est normal que la réaction essaye de semer la confusion dans les esprits, et de justifier ceux qui ne savent pas faire autrement qu'on ne faisait hier, en leur affirmant qu'ils sont de l'avant-garde. ${ }^{308}$

Ebenso wie der Futurismus ist der Surrealismus nun Teil der Kunstgeschichte, gemäß der Logik jenes «mouvement perpétuel de l'art», der vom «art d'avantgarde» über den «art moderne» zum «art traditionnel, classique» führt. ${ }^{309}$

Was wäre also «l'avant-garde dans l'art en 1958»? Le Monument, so Triolet, beschreibt «la naissance difficile d'une avant-garde qui porte le nom de réalisme socialiste». ${ }^{310}$ Diese «esthétique impossible» ${ }^{311}$ wird bei Triolet wie bei Aragon flexibel interpretiert und immer wieder remoduliert: «Selon les circonstances, il [Aragon] module sa définition du réalisme socialiste sans jamais en abandonner le principe [...]. Il s'efforce aussi de plaider pour une forme non contraignante,

306 Elsa Triolet: Le Monument, S. 172.

307 Elsa Triolet: L’Écrivain public, S. 83f.

308 Elsa Triolet: Maïakovski et nous, S. 68f.

309 Entretien sur l'avant-garde en art et Le Monument d'Elsa Triolet, S. 217f.

310 Ebda., S. 217.

311 Vgl. Régine Robin: Le Réalisme socialiste. Une esthétique impossible. Paris: Payot 1986. 
laissant au créateur l'imagination des formes à donner à son art.» ${ }^{312}$ Für Aragon funktioniert das Etikett auch als im Dienst der «construction de la lisibilité de sa propre trajectoire littéraire» verwendetes «argument biographique»; in diesem Sinne liest Philippe Olivera das Manifest Pour un réalisme socialiste (1935) als «une forme d'autobiographie littéraire». ${ }^{313}$

Triolet versucht ihrerseits, den Sozrealismus durch seine «base scientifique» zu legitimieren - und aus dem Zyklus herauszulösen, der jede Avantgarde im Museum enden lässt; vorstellbar sei eine ganze «succession d'avant-gardes qui relèveront du réalisme socialiste»: «L'original de l'histoire est que, pour la première fois, l'assimilation de ces avant-gardes par l'art n'enlèvera pas au réalisme socialiste le pouvoir d'inspirer les avant-gardes suivantes.» ${ }^{314}$ In Abgrenzung gegenüber einem Zugang, der künstlerische Innovation primär «dans l'inédit de la forme» verortet, ${ }^{315}$ definiert sie die sozrealistische Avantgarde über ihren neuen «point de vue» («[...] c'est pourquoi l'avant-garde de l'art nous intéresse, car, l'art nouveau, c'est celui qui jette une lumière nouvelle d'un point de vue nouveau, sur l'univers, sur l'homme [...]» $\left.{ }^{316}\right)$, ihren «angle de vue sur le monde»:

Il me semble que le réalisme socialiste est, dans le domaine de l'art, la première méthode ou théorie (ou, à mon avis personnel, ni méthode, ni théorie, mais angle de vue sur le monde) qui ait une base scientifique. En fait, cet angle de vue n'impose ni un contenu ni une forme ni des moyens particuliers... il ne s'impose que lui-même, laissant à l'artiste toute liberté de créer, pourvu que son œuvre adopte et propage cet angle de vue. Du moins est-ce ainsi que je comprends le réalisme socialiste. ${ }^{317}$

Diese etwas vage Terminologie ist theoretisch vielfach anschlussfähig, in Richtung des russischen Formalismus (Šklovskij versteht ostranenie auch als Über-

312 Alain Trouvé: La Lumière noire d'Elsa Triolet, S. 21.

313 Philippe Olivera: Aragon, «réaliste socialiste». Les usages d'une étiquette littéraire des années Trente aux années Soixante. In: Sociétés et Représentations 15, 1 (2003), S. 229-246, hier S. 242ff.; zit. nach Édouard Béguin: Aragon stalinien ou comment lire l'illisible. In: Recherches croisées Aragon/Elsa Triolet 11 (2007), S. 23-35, hier S. 25. Nuancierend ergänzt Béguin, dass der Sozialistische Realismus bei Aragon zwar «d'une certaine façon un mot vide», jedoch nicht exklusiv als «marqueur d'identité littéraire» zu analysieren sei: «Le terme est vide au regard de la théorie traditionnelle de la littérature, mais il est plein de ce qu'y met Aragon [...]» (ebda., S. 26).

314 Entretien sur l'avant-garde en art et Le Monument d'Elsa Triolet, S. 220.

315 Ebda.

316 Elsa Triolet: L’Écrivain public, S. 83. Vgl. zum «point de vue» oder «angle du réalisme socialiste» auch: Entretien sur l'avant-garde en art et Le Monument d'Elsa Triolet, S. 221.

317 Ebda., S. 220. 
windung des «point de vue unique sur les choses» ${ }^{318}$ ) wie in Richtung Paul Nizans, der an Aragons «réalisme socialiste» vor allem «sa capacité de perspectives» schätzt. ${ }^{319}$ Hier kommen wieder Migration als Faktor interkultureller Perspektivenpluralität und Gender als Matrix einer potentiell «avantgardistischen`Sichtweise ins Spiel: Liegt für Madeleine Braun der Reiz der Texte Triolets in ihrer Kombination eines «regard viril» und eines «clin d'œil féminin», ${ }^{320}$ so honoriert auch Nizan Triolet nicht zuletzt aufgrund ihrer «weiblichen〉 Vision - im Sinne nicht einer écriture féminine, sondern eines alternativen Blicks auf gesellschaftliche Realitäten - neben Malraux, Sartre und Aragon als Repräsentantin einer «politisch-literarischen Avantgarde». ${ }^{321}$

\section{Von Monument zu Monument: Metamorphosen der Muse (Conclusio)}

«[...] j'ai l'étrange sentiment que le destin de ce roman ne s'est pas encore entièrement accompli», schließt Triolet ihr Vorwort aus dem Jahr 1965. ${ }^{322} \mathrm{Ihr}$ Protagonist wird die Zukunft seiner "étape valable» ${ }^{323}$ nicht mehr erleben; sie selbst setzt ihre Reflexion über die Avantgarde-Problematik - wiederum illustriert an der Bildhauerei - in den Zwillingsromanen Le Grand Jamais (1965) und Écoutez-voir (1968) fort. Nicht Stalin gilt es diesmal ein Monument zu errichten, sondern ihrem Helden Régis Lalande - viel- und fehldiskutierter Historiker, der die Existenz jeglicher «vérité historique» negiert. ${ }^{324}$ Gewürdigt wird er mit einem «monument animé», das, als «perpetuum mobile» in Interaktion mit seiner Umgebung kon-

318 Marianne Delranc-Gaudric: Elsa Triolet, Maïakovski, Lili et Ossip Brik, Jakobson, Aragon..., S. 85.

319 Paul Nizan: Pour une nouvelle culture. Herausgegeben von Susan Suleiman. Paris: Grasset 1971, S. 177; zit. nach Alain Trouvé: La Lumière noire d'Elsa Triolet, S. 22.

320 Madeleine Braun: Elsa et les femmes. In: Europe 49, 506 (1971), S. 102-106, hier S. 106; zit. nach Elisa Borghino: L'identité féminine dans Les amants d'Avignon d'Elsa Triolet. In: Thomas Stauder (Hg.): L'identité féminine dans l'œuvre d'Elsa Triolet, S. 295-303, hier S. 298.

321 Unda Hörner: Das Romanwerk Elsa Triolets, S. 21.

322 Elsa Triolet: Préface à La Lutte avec l'ange, S. 22.

323 Elsa Triolet: Le Monument, S. 160.

324 «La vérité historique se trouve toujours entre les mains du pouvoir et change de camp avec lui», erklärt Elsa Triolet («Une goutte d'eau de la mer reproduit la mer». In: Euvres romanesques croisées d'Elsa Triolet et Aragon. Bd. 35: Le Grand Jamais. Paris: Laffont 1970, S. 14; zit. nach Lilly Marcou: Elsa Triolet, S. 365). 
zipiert, einem «gigantesque arbre exotique» ähnelt. ${ }^{325}$ Rund um dieses ambitionierte Denkmal inszeniert Triolet aufs Neue die Gratwanderung der Avantgarde zwischen ideologischer Vereinnahmung, Musealisierung und kommerzieller Verkitschung. Am Ende von Le Grand Jamais steht die Einweihung vor einer enthusiastischen Menschenmenge («La foule se mit à applaudir, à trépigner, à délirer» ${ }^{326}$ ); in Écoutez-voir hat sich das intendierte «monument inquiétant»» ${ }^{327}$ längst in einen «lieu de pèlerinage», ein «objet de bazar» verwandelt. ${ }^{328}$ Hier zeigt sich wieder die Ambivalenz eines rezeptionsfokussierten Avantgarde-Begriffs, der den Leser/ Betrachter rhetorisch zum Ko-Kreateur adelt - um daraufhin den Verlust der eigenen Deutungshoheit und die inadäquate Attitüde der Plebs zu beklagen.

Als Fehl-Interpretin tritt in Le Grand Jamais aber auch Madeleine Lalande in Erscheinung, junge Witwe des Denkers und Geliebte des Künstlers. Enttäuscht stellt sie am Ende des Romans fest, dass ihre Idee für das Denkmal «à la gloire de mon mari» ${ }^{329}$ ignoriert wurde - und verschwindet in einer doppelsinnigen «perspective»: «Elle s'éloignait du monument et, vue de la place, se faisait de plus en plus petite: la perspective s'était emparée d'elle.. ${ }^{330}$ In Écoutez-voir taucht diese Nebenfigur wieder auf - als elegante rôdeuse («- Je suis clocharde. / - Où? Chez Dior?» ${ }^{331}$ ), doch vor allem als höchst selbstreflexive Protagonistin, die unablässig ihren eigenen fiktionalen Status thematisiert, sich fragt, ob sie ihrer neuen Würde wohl gewachsen sei («'ai déjà existé sur les pages d'un roman. Pas pour moi; pour lui. Lui, roman, lui, son personnage principal. [...] Moi, Madeleine Lalande. Est-ce que toute seule je fais encore le poids?» ${ }^{332}$ ), während sie ihre Rolle als bewährte Muse mit selbstironischer Routine weiterspielt. «Elle est l'étincelle qui, si vous êtes un bidon d'essence, vous fait flamber. [...] L'extraordinaire femme!», begeistert sich Austin. ${ }^{333}$ «Je pense à Austin, j’ai idée qu'il ne fera pas

325 Elsa Triolet: Le Grand Jamais. Paris: Gallimard 1977 [1965], S. $370 \mathrm{f}$.

326 Ebda., S. 371.

327 Elsa Triolet: Écoutez-voir, S. 344; vgl. auch dies.: Le Grand Jamais, S. 372.

328 Elsa Triolet: Écoutez-voir, S. 344.

329 Ebda., S. 64.

330 Elsa Triolet: Le Grand Jamais, S. 374.

331 Elsa Triolet: Écoutez-voir, S. 250.

332 Ebda., S. 11f. «Moi, roman; moi, son personnage principal» (ebda., S. 73), wundert sich Madeleine quer durch den Roman - und erschrickt, als ihr «créateur» (in der maskulinen Form adressiert) sie plötzlich im Stich zu lassen scheint: «Mon créateur me laisse seule? Je n’aurais donc plus besoin d'autres personnages pour mes trois dimensions? Pourquoi me faire ça?» (ebda., S. 223).

333 Ebda., S. 157. 
long feu sur ces pages [...]», ${ }^{334}$ kommentiert trocken Madeleine. Sie problematisiert nicht nur die Konstruktion 〈ihres〉 Romans, sondern auch die 〈große〉 (männliche) Geschichte; so manifestiert sie anlässlich einer florentinischen Besichtigungstour «quelque irritation»: «il semblait bien que l'Histoire, digérée par le guide, ne l'intéressait pas», wie ihr Begleiter beobachtet. ${ }^{335}$

Triolet zufolge ist dieser zweite Roman auf Anregung, ja «Bestellung〉 ihrer Leserschaft enstanden, hatte diese doch Madeleine als die eigentliche Hauptfigur von Le Grand Jamais wahrgenommen und eine entsprechende Alternativversion bzw. Fortsetzung eingefordert. Jenes Monument, in dem Madeleine sich während der editorialen und diegetischen Ellipse zwischen den beiden Texten versteckt («Et moi, pendant toutes ces années, avant ma rencontre avec le monument et après, j'ai existé» ${ }^{336}$ ), fungiert als mise en abyme der Entstehungsgeschichte wie der Romanhandlung insgesamt. Erst in Écoutez-voir wird der Muse im Rahmen einer regelrechten «révélation» ${ }^{337}$ klar, dass das Denkmal ihres illustren Gatten sie selbst enthält: Dank Photovoltaik setzt sich das Konstrukt in Bewegung, öffnen sich «les volets d'une sorte de tabernacle et l'on voit alors, à l'intérieur, une grande tête de femme - à ce qu'on dit le portrait de la veuve de Régis Lalande - qui regarde chacun droit dans les yeux». 338

Dieses Bild der unsichtbaren Frau im Herzen des doppelt männlichen Monuments, die - in einem weiblich autorisierten avantgardistischen Collageroman nur bei entsprechender Beleuchtung und Perspektive zum Vorschein kommt, lädt zu einer poetologischen Interpretation ein. Symptomatisch die Umstände, unter denen Madeleine aus einem Zeitungsbericht vom Geheimnis des abgründigen Kunstwerks erfährt: Bei einem vandalistischen Akt wurde ebenjene «tête de femme» attackiert und mit Fäkalien beschmutzt. ${ }^{339}$

Und dennoch blickt die bald ver-, bald enthüllte Frauenfigur stolz in die Menge, um den Hals, «comme un collier noir et brillant, ces mots: À TouT À L'HEURE ${ }^{340}$ - polysemische Inschrift, die die Ambivalenzen der Avantgarde zwi-

334 Ebda., S. 224.

335 Ebda., S. 38.

336 Ebda., S. 15.

337 Ebda., S. 314.

338 Ebda., S. 66.

339 Ebda., S. 314ff. «C'est ma tête qui en avait, paraît-il, plein les yeux, les joues, la bouche... [...] En somme, si on n'a pas enfoncé des épingles dans mes yeux, c'est que la matière en est trop dure. [...] Régis s'en sort toujours mieux que moi: [...] et c'est moi qu'on a barbouillée de merde à sa place. À moins que ce soit moi qu'on ait visée, directement?» (ebda., S. 317f.).

340 Elsa Triolet: Le Grand Jamais, S. 370. 
schen Kunst und Politik, Vergangenheit, «Gegenwartsorientierung» ${ }^{341}$ und Zukunft, zwischen den Geschlechtern schließlich auch brillant resümiert.

\section{Literaturverzeichnis}

Asholt, Wolfgang/Walter Fähnders: 〈Projekt Avantgarde`. Vorwort. In: dies. (Hg.): «Die ganze Welt ist eine Manifestation». Die europäische Avantgarde und ihre Manifeste. Darmstadt: Wiss. Buchgesellschaft 1997, S.1-17.

Balachova, Tamara: Le double destin d'Elsa Triolet en Russie (Documents des Archives moscovites). In: Marianne Gaudric-Delranc (Hg.): Elsa Triolet. Un écrivain dans le siècle. Paris: L'Harmattan 2000, S. 93-101.

Béguin, Édouard: Aragon stalinien ou comment lire l'illisible. In: Recherches croisées Aragon/ Elsa Triolet 11 (2007), S. 23-35.

Biasiolo, Monica: Écrire dans (et avec) la langue de l'autre. Elsa Triolet et Vladimir Maïakovski entre biographie et textes. In: Thomas Stauder (Hg.): L'identité féminine dans l'œuvre d'Elsa Triolet. Tübingen: Narr 2010, S. 59-80.

Borghino, Elisa: L'identité féminine dans Les amants d'Avignon d'Elsa Triolet. In: Thomas Stauder (Hg.): L'identité féminine dans l'œuvre d'Elsa Triolet. Tübingen: Narr 2010, S. 295303.

Bouchardeau, Huguette: Elsa Triolet. Écrivain. Paris: Flammarion 2000.

Bourdieu, Pierre: Méditations pascaliennes. Paris: Seuil 1997.

Brodsky, Joseph: Der Zustand, den wir Exil nennen, oder Leinen los [1987]. In: Der sterbliche Dichter. Über Literatur, Liebschaften und Langeweile. Frankfurt a. M.: Fischer 2000 [On Grief and Reason, 1995], S. 31-46.

Bürger, Peter: Theorie der Avantgarde. Frankfurt a. M.: Suhrkamp 1974.

Cainer, Rudla: Žulový Stalin. Osudy pomníku a jeho autora. Praha: ARSCI 2008.

Cassin, Barbara (Hg.): Vocabulaire européen des philosophies. Dictionnaire des intraduisibles. Paris: Seuil 2004.

Chadourne, Marc: Vasco. Paris: Plon 1927.

Cvetaeva, Marina: Toska po rodine! Davno... [1934]. In: Stichotvorenija. Poèmy. Moj Puškin. Moskva: Olma 2000, S. 280-281.

Delranc-Gaudric, Marianne: D'Эльза Tриоле à Elsa Triolet. Les quatre premiers romans d'Elsa Triolet et le passage du russe au français. Diss., Paris: INALCO 1991.

Delranc-Gaudric, Marianne: L'accueil critique des premiers romans d'Elsa Triolet en Union soviétique. In: Recherches croisées Aragon/Elsa Triolet 6 (1998), S. 13-36.

Delranc-Gaudric, Marianne: Elsa Triolet et la vision politique d'Aragon. In: Recherches croisées Aragon/Elsa Triolet 11 (2007), S. 49-58.

Delranc-Gaudric, Marianne: Elsa Triolet, Maïakovski, Lili et Ossip Brik, Jakobson, Aragon... Une constellation créatrice (Les Lettres françaises, 1968). In: Recherches croisées Aragon/Elsa Triolet 13 (2011), S. 83-91.

Duranti, Andrea: Elsa Triolet. Une vie étrangère. In: Thomas Stauder (Hg.): L'identité féminine dans l'œuvre d'Elsa Triolet. Tübingen: Narr 2010, S. 319-334.

341 Wolfgang Asholt/Walter Fähnders: «Projekt Avantgarde`, S. 10. 
Efthymiou, Loukia: Genre, discours et engagement chez Elsa Triolet. In: Thomas Stauder ( $\mathrm{Hg}$.): L'identité féminine dans l'œuvre d'Elsa Triolet. Tübingen: Narr 2010, S. 223-235.

Eychart, Marie-Thérèse: Préface. Elsa Triolet dans la bataille idéologique et littéraire de l'aprèsguerre. In: Elsa Triolet: L'Écrivain et le livre ou La Suite dans les idées. Bruxelles: Aden/ Société des Amis de Louis Aragon et Elsa Triolet 2012 [1948], S. 5-21.

Febel, Gisela: «Poesie-Erreger» oder von der signifikanten Abwesenheit der Frau in den Manifesten der Avantgarde. In: Wolfgang Asholt/Walter Fähnders (Hg.): «Die ganze Welt ist eine Manifestation». Die europäische Avantgarde und ihre Manifeste. Darmstadt: Wiss. Buchgesellschaft 1997, S. 81-108.

Flusser, Vilém: Exil und Kreativität [1984/1985]. In: Von der Freiheit des Migranten. Einsprüche gegen den Nationalismus. Hamburg: Europäische Verlagsanstalt 2007 [1994], S. 103-109.

Forest, Philippe: Aragon/Tel Quel. Un chassé-croisé. In: Recherches croisées Aragon/Elsa Triolet 11 (2007), S. 105-114.

Groys, Boris: Gesamtkunstwerk Stalin. Die gespaltene Kultur in der Sowjetunion. München: Hanser 1996 [1988].

Hörner, Unda: Das Romanwerk Elsa Triolets. Im Spannungsfeld von Avantgarde und Sozialistischem Realismus. Essen: Die Blaue Eule 1993.

Hörner, Unda: Die realen Frauen der Surrealisten. Simone Breton, Gala Éluard, Elsa Triolet. Frankfurt a. M.: Suhrkamp 1998.

(Koll.): Entretien sur l'avant-garde en art et Le Monument d'Elsa Triolet. Extraits. In: Elsa Triolet: Le Monument. Paris: Gallimard 1976 [1957], S. 217-241.

Kristeva, Julia: Étrangers à nous-mêmes. Paris: Gallimard 1991 [1988].

Lushenkova Foscolo, Anna: Les écrivains de langue russe en exil. Plurilinguisme et autotraduction. In: Martina Stemberger/Lioudmila Chvedova (Hg.): Littératures croisées. La langue de l'autre. Fragments d'un polylogue franco-russe (XXe-XXIe siècles). Nancy: PUN - Éditions Universitaires de Lorraine 2017, S. 179-192.

Marcou, Lilly: Elsa Triolet. Les Yeux et la Mémoire. Paris: PLON 1994.

Melville, Herman: Moby-Dick, or The Whale. Ware, Hertfordshire: Wordsworth 1993 [1851].

Měštan, Antonín: Elsa Triolet in der russischen Literatur. In: Wiener Slawistischer Almanach 14 (1984), S. 153-165.

Mládková, Jitka: Stalin-Monstermonument. Vor 50 Jahren auf Befehl aus Moskau gesprengt. 21. April 2012. http://www.radio.cz/de/rubrik/geschichte/stalin-monstermonument-vor60-jahren-auf-befehl-aus-moskau-gesprengt [10.02.2018].

Morel, Jean-Pierre: Le Roman insupportable. L'Internationale littéraire et la France. 1920-1932. Paris: Gallimard 1985.

Nadolny, Susanne: Elsa Triolet (1896-1970). Glückssuche an der Schreibmaschine. In: dies. (Hg.): Gelebte Sehnsucht. Grenzgängerinnen der Moderne. Berlin: Ebersbach 2005, S. 149-175.

Nivat, Georges: Russie-Europe. La Fin du schisme. Études littéraires et politiques. Lausanne: L'Âge d'Homme 1993.

Oldenbourg, Zoé: Visages d'un autoportrait. Paris: Gallimard 1977.

Poulton, Leslee: The Influence of French Language and Culture in the Lives of Eight Women Writers of Russian Heritage. Lewiston u. a.: The Edwin Mellen Press 2002.

Raeff, Marc: Russia Abroad. A Cultural History of the Russian Emigration. 1919-1939. New York/ Oxford: Oxford University Press 1990.

Robel, Léon: Un destin traduit. La Mise en mots d'Elsa Triolet. In: Marianne Gaudric-Delranc (Hg.): Elsa Triolet. Un écrivain dans le siècle. Paris: L'Harmattan 2000, S. 19-32.

Robin, Régine: Le Réalisme socialiste. Une esthétique impossible. Paris: Payot 1986. 
Said, Edward W.: Reflections on Exile. In: Reflections on Exile and Other Essays. London: Granta 2012 [2000], S. 173-186.

Spivak, Gayatri Chakravorty: The Spivak Reader. Selected Works of Gayatri Chakravorty Spivak. Herausgegeben von... Donna Landry/Gerald MacLean. New York/London: Routledge 1996.

Stemberger, Martina: Les mots des autres - en d'autres mots. (In-)traductibilité, identité et altérité dans le dialogue franco-russe de l'entre-deux-guerres. In: M. Stemberger/Lioudmila Chvedova (Hg.): Littératures croisées. La langue de l'autre. Fragments d'un polylogue francorusse (XXe-XXIe siècles). Nancy: PUN - Éditions Universitaires de Lorraine 2017, S. 193-225.

Stephan, Inge: Zwischen Provinz und Metropole. Zur Avantgarde-Kritik von Marieluise Fleißer. In: I. Stephan/Sigrid Weigel (Hg.): Weiblichkeit und Avantgarde. Berlin/Hamburg: Argument 1987, S. 112-132.

Suleiman, Susan Rubin: Subversive Intent. Gender, Politics, and the Avant-Garde. Cambridge, Mass./London: Harvard University Press 1990.

Tippner, Anja: «Aller et retour, ou aller seulement, sans retour». Exil als Lebensform und Metapher bei Elsa Triolet und Viktor Šklovskij. In: Lyubov Bugaeva/Eva Hausbacher (Hg.): Ent-Grenzen. Intellektuelle Emigration in der russischen Kultur des 20. Jahrhunderts. Frankfurt a. M. u. a.: Lang 2006, S. 105-127.

Triolet, Elsa: Maïakovski et nous. Pour le dix-septième anniversaire de la mort de Vladimir Maïakovski [1947]. In: L'Écrivain et le livre ou La Suite dans les idées. Bruxelles: Aden/ Société des Amis de Louis Aragon et Elsa Triolet 2012 [1948], S. 25-80.

Triolet, Elsa: L’Écrivain public [1947]. In: L'Écrivain et le livre ou La Suite dans les idées. Bruxelles: Aden/Société des Amis de Louis Aragon et Elsa Triolet 2012 [1948], S. 81-87.

Triolet, Elsa: Prenez exemple sur nos ennemis [1948]. In: L'Écrivain et le livre ou La Suite dans les idées. Bruxelles: Aden/Société des Amis de Louis Aragon et Elsa Triolet 2012 [1948], S. 89117.

Triolet, Elsa: Ce que disent de la crise du livre les gens connus et les gens inconnus [Annexes]. In: L'Écrivain et le livre ou La Suite dans les idées. Bruxelles: Aden/Société des Amis de Louis Aragon et Elsa Triolet 2012 [1948], S. 123-138.

Triolet, Elsa: Histoire d'Anton Tchekhov. Sa vie, son œuvre. Paris: Éd. français réunis 1954.

Triolet, Elsa: Le Rendez-vous des étrangers. Paris: Gallimard 1956.

Triolet, Elsa: Le Monument. Paris: Gallimard 1976 [1957].

Triolet, Elsa: Ouverture. In: CFuvres romanesques croisées d'Elsa Triolet et Aragon. Bd. 1: À Tahiti. Bonsoir, Thérèse. Les Manigances. Paris: Laffont 1964, S.11-47.

Triolet, Elsa: Bonsoir, Thérèse. In: EFuvres romanesques croisées d'Elsa Triolet et Aragon. Bd. 1: À Tahiti. Bonsoir, Thérèse. Les Manigances. Paris: Laffont 1964, S. 145-292.

Triolet, Elsa: Le Grand Jamais. Paris: Gallimard 1977 [1965].

Triolet, Elsa: Préface à La Lutte avec l'ange [1965]. In: Le Monument. Paris: Gallimard 1976 [1957], S. 7-22.

Triolet, Elsa: Écoutez-voir. Paris: Gallimard 1968.

Triolet, Elsa: La Mise en mots. Genève: Albert Skira 1969 (Les Sentiers de la création).

Triolet, Elsa: Le rossignol se tait à l'aube. Paris: Gallimard 1970.

Trouvé, Alain: La Lumière noire d'Elsa Triolet. Lyon: ENS Éditions 2006.

Trouvé, Alain: Roman et différence sexuelle chez Elsa Triolet et Aragon. In: Thomas Stauder (Hg.): L'identité féminine dans l'œuvre d'Elsa Triolet. Tübingen: Narr 2010, S. 99-119.

Tsvétaeva, Marina: Poèmes. Traduits par Elsa Triolet. Paris: Gallimard 1968.

Vassevière, Maryse: Aragon, Breton et la peinture soviétique. In: Recherches croisées Aragon/ Elsa Triolet 13 (2011), S. 95-119. 
Weigel, Sigrid: Hans Bellmer Unica Zürn. Junggesellenmaschinen und die Magie des Imaginären. In: Inge Stephan/S. Weigel (Hg.): Weiblichkeit und Avantgarde. Berlin/Hamburg: Argument 1987, S. 187-230.

Weigel, Sigrid: 〈Frauen` und ১Juden` in Konstellationen der Modernisierung. Vorstellungen und Verkörperungen des internen Anderens. Ein Forschungsprogramm. In: Inge Stephan/Sabine Schilling/S. Weigel (Hg.): Jüdische Kultur und Weiblichkeit in der Moderne. Köln/Weimar/Wien: Böhlau 1994, S. 333-351. 